\title{
WASHed Up? \\ An Analysis of Water Access, Sanitation and Hygiene Programmes
}

by

Brian Enright

A thesis submitted to the Faculty of Graduate and Postdoctoral Affairs in partial fulfillment of the requirements for the degree of

Master of Arts

in

Sociology

Carleton University

Ottawa, Ontario

(C) 2013, Brian Enright 
Library and Archives

Canada

Published Heritage

Branch

395 Wellington Street

Ottawa ON K1A ON4

Canada
Bibliothèque et

Archives Canada

Direction du

Patrimoine de l'édition

395 , rue Wellington

Ottawa ON K1A ON4

Canada
Your file Votre référence

ISBN: 978-0-494-94600-8

Our file Notre référence

ISBN: $978-0-494-94600-8$
NOTICE:

The author has granted a nonexclusive license allowing Library and Archives Canada to reproduce, publish, archive, preserve, conserve, communicate to the public by telecommunication or on the Internet, loan, distrbute and sell theses worldwide, for commercial or noncommercial purposes, in microform, paper, electronic and/or any other formats.

The author retains copyright ownership and moral rights in this thesis. Neither the thesis nor substantial extracts from it may be printed or otherwise reproduced without the author's permission.
AVIS:

L'auteur a accordé une licence non exclusive permettant à la Bibliothèque et Archives Canada de reproduire, publier, archiver, sauvegarder, conserver, transmettre au public par télécommunication ou par l'Internet, prêter, distribuer et vendre des thèses partout dans le monde, à des fins commerciales ou autres, sur support microforme, papier, électronique et/ou autres formats.

L'auteur conserve la propriété du droit d'auteur et des droits moraux qui protege cette thèse. $\mathrm{Ni}$ la thèse ni des extraits substantiels de celle-ci ne doivent être imprimés ou autrement reproduits sans son autorisation.
In compliance with the Canadian Privacy Act some supporting forms may have been removed from this thesis.

While these forms may be included in the document page count, their removal does not represent any loss of content from the thesis.
Conformément à la loi canadienne sur la protection de la vie privée, quelques formulaires secondaires ont été enlevés de cette thèse.

Bien que ces formulaires aient inclus dans la pagination, il n'y aura aucun contenu manquant. 


\section{Abstract}

The world is currently facing a water crisis. An estimated 780 million people currently lack access to healthy clean water and an additional 2.5 billion are without access to basic sanitation. These populations are frequently crippled by disease, minimal education and limited economic opportunities. This thesis is about water access, sanitation and hygiene (WASH) programmes, which offer a potential solution to the water crisis by providing these populations with water and sanitation facilities along with hygiene and water treatment education. Regrettably, WASH programmes are facing a crisis of sustainability, as upwards of half of all WASH programmes result in populations ignoring the improved WASH-related practices or reverting to their previous unhealthy activities. Explanations for why this is the case tend to be ad-hoc and lacking theoretical coherence. This thesis offers an explanation for why WASH is failing, by operationalizing a framework to explore why programmes are not achieving long-term changes in the actions of these populations followed by recommendations how these programmes should change, so the improved actions are accepted, adopted and, ideally, last for generations. 


\section{Acknowledgements}

First and foremost, my sincere gratitude and abundant appreciation are owed to Dr. George Pollard for overseeing and advising me throughout this study, as well as inspiring me from the first day I set foot in your introduction to Sociology almost ten years ago.

Thanks to the faculty and staff at Carleton, particularly Dr. Danielle DiNovelliLang for her invaluable comments on my draft and to Dr. Hymie Anisman for participating in my defense. Thanks to Dr. Amina Mire for her support and guidance, and to Paula Whissell for her kindness and helpfulness, without her support I would still be looking for forms on the Carleton website, likely missing a number of deadlines along the way.

Thanks also to Karen Tucker for "wordslaying" the typos, grammatical errors, and oxford commas that would otherwise be littered throughout this document, and to Cathy Enright and Dan Lenko for ensuring the quality and clarity of my work. Thanks, as well, to Melayna Simister for her daily support and help editing, critiquing and talking through countless ideas in the development of this document.

Many thanks to Fabian Suter and Dr. Alexandra Huber of EAWAG; to Dr. Corinne Schuster Wallace of the United Nations University Institute for Water, Environment and Health; and to Sean Furey of the Rural Water Supply Network. Thank you all for your time and insight into my research, your perspectives were infinitely helpful in steering the direction and scope of this study.

Finally, it took a village of my family, friends and colleagues to encourage, support and believe in me throughout this rewarding and challenging process. Thank you, my village; I couldn't have done it without you. 


\section{Table of Contents}

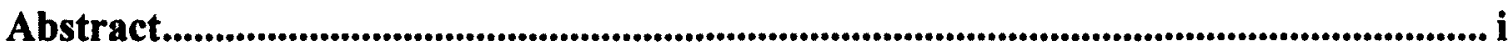

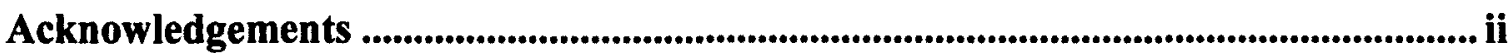

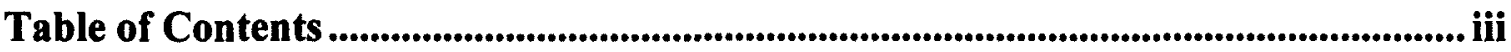

List of Appendices.......................................................................................................................... iv

Preface.............................................................................................................................................................. v

1 Chapter: The Water Crisis ............................................................................................................ 1

2 Chapter: The Sustainability Crisis........................................................................................ 16

3 Chapter: A Theory for WASH ........................................................................................ 37

4 Chapter: Application of Theory ...................................................................................6 60

5 Chapter: Conclusions ........................................................................................................ 94

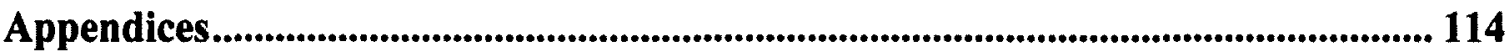

Appendix A : Relationship of Water and Sanitation towards the Millennium Development

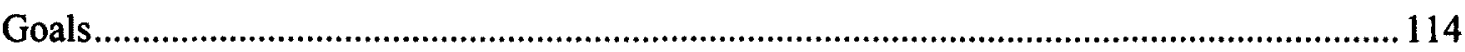

Appendix B : Diagram of the Fecal-Oral Transmission of Germs and Ways to Break the

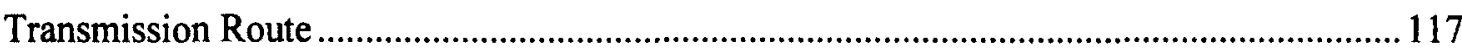

Bibliography .......................................................................................................................... 118 


\section{List of Appendices}

Appendix A : Relationship of Water and Sanitation towards the Millennium Development

Goals...

114

Appendix B : Diagram of the Fecal-Oral Transmission of Germs and Ways to Break the

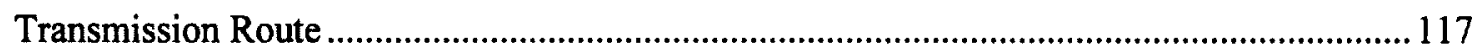




\section{Preface}

This study was born of two principle objectives: to align the research and topic with something in the field of international development, particularly in a macro-policyrelated domain where there is interest from the United Nations (UN) or World Health Organization (WHO); and to do so using quantitative methods, to develop further skills for future job prospects, as well.

With these goals in mind, I began researching topics related to the UN/WHO with a focus on Canada and subjects with readily available data. Water became the obvious choice, given Canada's abundance of it, and the UN's numerous interests in it globally. In comparing the freshwater available in Canada to other regions around the world, I was shocked to learn that sub-Saharan Africa is among the most water rich areas in the world yet, as a region, has the highest proportion of the population without access to clean and safe water. I was perplexed by this, one of the most water-rich areas in the world with an unnecessarily large proportion of the population literally dying for water.

This realization led to an interest in the Millennium Development Goals (MDGs). International efforts to track the MDGs generate a large volume of readily available data. At the time, the most recent reports related to the MDGs warned many of the goals were not attainable at the current rate of progress; particularly, the goal related to water (WHO/UNICEF JMP, 2010). Further research began to examine why the goals were off track, for which I thought that given the abundance of available data, it would be possible to find an answer through quantitative analysis.

The amount of data at this level was overwhelming; the data first needed some narrowing in its range and scope before proceeding. Further research to refine the 
approach brought the issues of improved water and sanitation to the forefront due to the overlapping benefits they bring to one another and the MDGs as a whole. This is because, clean water enhanced by sanitation, is the base upon which many other development opportunities become possible.

From here I discovered the UN and WHO promoted Water Access, Sanitation and Hygiene (WASH) programmes, which offer a solution to these water and sanitation challenges. I began to research WASH programmes more intently as they appeared a more manageable lens for the data analysis. At the same time, it quickly became apparent that the design of WASH programmes is far from homogeneous; delivered and implemented by numerous organizations with different techniques, levels of funding and reporting methods. The data on programmes, when available, was scattered and not easily comparable between different programmes from different implementing organizations, posing a problem for attaining a coherent view. Putting concerns over the data aside, I continued to research the subject of WASH because I had become convinced these programmes were a part of the solution to greater progress towards the MDGs and thought that, perhaps it would be possible to find a way for programmes to be more effective.

From here the research took an interesting and important shift, turning away from the websites of organizations implementing programmes to a number of online spaces where WASH practitioners were discussing the programmes on a more candid level. Through discussions on message boards and a number of online debates, participants were reporting that WASH programmes were facing a number of challenges. These included mentions of poor data-sharing between organizations; lack of follow-up 
post-implementation; calls for greater levels of government support; instances of programme-supplied facilities lasting far less time than was intended; and the most common issue of communities not adopting the practices being taught by the programmes. The overarching sentiment was that WASH programmes can, and must do better.

It was in these comments that propelled my research question: why are WASH programmes failing and what can anything be done to make them more successful? Given the disconnect between the implementing organizations and WASH practitioners, it was clear that comparable and reliable data was not going to be available for a quantitative analysis; qualitative methods were, therefore, necessary to proceed.

In answering this research question, the first chapter of this thesis begins by outlining the importance of access to water and sanitation towards combating poverty and improving economic and educational outcomes. Improving the health, education and economic opportunities of current populations will empower the current generation to raise future generations without the same level of poverty. Water and sanitation, are therefore, a priority for efforts from numerous international aid organizations to improve the living conditions of the global population.

WASH programmes are a crucial part of the solution to solving these waterrelated challenges. Regrettably, these programmes are failing at an alarming rate with upwards of half failing to change the water and sanitation activities of the targeted populations. Chapter two examines how WASH programmes are failing, with an in-depth focus on three exemplars of failed programmes that were implemented in Guatemala, Malawi, and Kenya, demonstrating the widespread and disparate nature of the failure. In 
general terms, failed WASH programmes are not succeeding at encouraging communities to retain the improved water- and sanitation-related practices, such as choosing clean water sources, treating water as needed, stopping open defecation, maintaining and repairing facilities as required, and hand-washing at critical times. Despite numerous different techniques and methods to supply the necessary facilities and resources, education and training, these populations are commonly reverting to their previous unhealthy activities.

The literature offers numerous reasons why suggested actions, taught by WASH programmes, were abandoned pointing to external factors such as: programmes frequently inconsistent with the cultures and needs of the targeted populations; programme methods that are too expensive for the communities to continue; or that the implementation overemphasizes building facilities at the expense of educating the local populations about the benefits and risks. Although each of these factors is important to success of WASH programmes they tend to be ad hoc and, individually, are not sufficient to explain the extent of this widespread failure.

The next chapter contextualizes the high rate of programme failure by unifying a theory, based primarily on Berger and Luckman (1966) to explain why these programmes are frequently unsuccessful. By operationalizing core concepts from Berger (1967), Harris (1966; 1979), Durkheim (1933; 1982), Pareto (1966), Parsons (1968) and Cooley (1909), chapter three lays out a theory arguing that current programmes are not sufficiently considering the importance of the sociological factors necessary for longterm adoption of WASH practices. Although the ad hoc reasons for failure are important 
if not also addressed, changing the underlying social elements that direct and reinforce human activity is crucial to programme success.

Chapter four applies the theory to the exemplars of failed WASH programmes, outlined in chapter two. In all three cases, researchers misattribute the reasons for programme failure, missing that underlying social conditions necessary for programme success were absent. Instead, the reasons provided, for failure, are secondary to the lack of change in the social reality of these communities. Without addressing the social reality, these programmes were doomed to failure from the beginning.

Finally, chapter five presents a meaningful explanation for why these programmes are failing, followed by a number of recommendations to improve the success rate of future programmes. This chapter explains how WASH programmes are not giving communities a chance to have the improved water- and sanitation-related activities accepted long-term because they are not sufficiently addressing the underlying social system that directs human activity. Successful programmes that encourage long-term adoption of the new WASH-related actions require communities and individuals to choose to continue the WASH-related practices. Ultimately, target populations of WASH programmes must recognize the long-term importance of WASH to their communities, families and themselves. To ensure this outcome, WASH programmes must provide sufficient time to instill the long-term benefits to those targeted for help. Whenever an individual is faced with a decision to continue the practices or revert, continuation must be the obvious choice every time; and the key to achieving this objective lies in programmes addressing how members of target communities view the world. 


\section{Chapter: The Water Crisis}

Every day, hundreds of millions of people drink, as well as cook and clean with cloudy, potentially contaminated water. Given the opportunity, they would almost certainly opt for clear water but, too often, cloudy and contaminated is the only option, and the way their water has always been. Whatever water is available has to be good enough.

This document is about Water Access, Sanitation and Hygiene (WASH) programmes, which attempt to help these populations by promoting awareness of the risks of drinking water like this, while providing various types of treatment options, along with water and sanitation facilities and hygiene education. Unfortunately, these programmes are failing at an alarming rate. Estimates suggest that upwards of half of all WASH programmes fail. Explanations for why are not compelling and lack a unifying theory to explain the high incidence of programme failure.

Consequently, this study will explore why WASH programmes are failing by operationalizing a theory and applying it to a number of reports on failed programmes. The result is a unifying theory that explains why these programmes are frequently ineffective at changing the water- and sanitation-related activities of these populations, followed by a number of recommendations to improve future programmes.

Physiologically, water is crucial for hydration of the human body, the production of the food and sanitation to maintain health. Economically, water is a commodity to be bought and sold. Water also has a social component pertaining to the roles of those who collect it and are responsible for it, and it is integrally tied to education, health and social 
status. Once explained in terms of its social importance, it is difficult to separate the two realities. Physiologically, economically and socially, access to water is literally a matter of life or death.

The global water supply currently faces a humanitarian crisis as water scarcity affects one out of every four people worldwide. Water-scarce populations face a number of challenges including insufficient water for livestock and agriculture, unsanitary and unhealthy living conditions and spend large proportions of time and income securing water. These challenges are most commonly experienced by populations in the least developed countries and pose a major barrier to development opportunities. Despite considerable effort by donor countries and international development and aid organizations, basic issues of water access and inadequate sanitation persist for many less developed countries. Roughly one-third of the global population currently lives in countries with moderate-to-high water scarcity. The United Nations (UN) expects that by $2025,1.8$ billion people could be living in regions facing water scarcity (United Nations Development Programme, 2006). For water-scarce countries, this is a serious threat; for water-rich countries the threat is less severe and, should instead, be considered in terms of the extensive geo-political consequences. Addressing these future challenges begins with improving management of freshwater resources in the present.

The key to understanding the water crisis is to consider the amount of freshwater on the planet, its use and location and more importantly, the human toll on its availability. There is an abundance of water on the planet, thousands of times more than the amount humans appropriate for use every year, yet the vast majority of it, 97.5 percent, is salt water and unfit for human consumption (Gleick et al., 2009). The remaining 2.5 percent 
is freshwater, of which more than two-thirds is unattainable, trapped in glaciers, snow and permafrost (Gleick et al., 2009). The remainder leaves less than one percent of the total water on the planet available for human consumption.

Freshwater is a finite resource and human intervention has contributed to less freshwater availability (Caso, 2010: p.4). On a global level the vast majority of the freshwater supply is used for agricultural purposes, industrial processes make up the second largest use of freshwater, whereas domestic use accounts for only a relatively small percentage of the total freshwater usage. All of these processes take a toll on the availability and quality of freshwater.

Access to clean, safe and adequate freshwater is crucial to the survival of all living organisms and to the health of ecosystems, communities and economies. At the macro-level, contamination of water in natural ecosystems affects billions of humans by destroying biodiversity, aiding contaminants to enter the food chain and destroying the natural ability of ecosystems to naturally purify water. At the micro-level, contamination of water directly affects millions by reducing the availability of safe water for drinking, compromising health and limiting economic productivity and development opportunities.

Much of the available freshwater has been polluted by industrial toxins, agricultural run-off, improper irrigation, deforestation, draining of wetlands and diverting rivers, as well as improper treatment of human waste (Caso, 2010). Roughly 70 percent of the world's freshwater supply is used for agricultural purposes, with industrial processes consuming an additional 22 percent (Caso, 2010). With over 90 percent of global freshwater being used for agricultural and industrial uses, this leaves domestic and 
municipal use consuming only a fraction of total water use worldwide, roughly eight percent (Caso, 2010).

The World Health Organization (WHO) indicates inadequate quantity or quality of water causes approximately 3.1 percent of all deaths worldwide each year (as cited in Gleick et al., 2011). The majority of these water-related deaths are the result of microbial contaminants, either in contaminated water or spread through unhygienic practices, or from lack of sanitation as a result of contaminated water or insufficient amounts of water for proper sanitation. Water contaminated by human or animal excrement is the main cause of the poor water quality and the main cause of water-related diseases (Gleick et al., 2011: p.57).

In developing countries, nearly 80 percent of diseases are associated with poor water quality and improper sanitation (WHO/UNICEF, 2006). Waterborne diseases are those where water is the agent of transmission, whereby pathogens are transmitted from excrement to water to humans, often the result of improper treatment of human excreta, particularly associated with open defecation. The resulting diseases are mostly diarrheal in nature, caused by bacteria, parasites and viruses from contaminated drinking water (Gleick et al., 2011:p.57). The single most effective intervention is hand-washing with soap, which limits exposure to these pathogens at critical points, such as eating, as well as contamination of domestic water reserves. Despite the relative simplicity of handwashing with soap, roughly 1.8 million people die unnecessarily each year from diarrheal diseases linked to contaminated water (WHO/UNICEF, 2006). Worldwide, water-related diseases are one of the leading causes of death for children under five years old (Gleick et al., 2011: p, 57). 
The United Nations Children's Fund (UNICEF) estimates that in developing countries, children often suffer from four to five debilitating episodes of diarrhea a year (as cited in Gleick et al., 2011: p.58). For survivors, malnutrition is a constant risk, especially when illnesses are severe or repeated. It is estimated that malnutrition, as a result of unsafe water, is responsible for 35 percent of all deaths of children aged five years or younger (Gleick, 2011: p.57). UNICEF (as cited in Gleick et al., 2011: p.58) has shown a link between years of chronic diarrhea and long-term cognitive impairment and stunting. In addition, numerous other water-borne diseases, such as typhoid fever and forms of hepatitis, needlessly kill 600,000 people per year, due to ingestion of water contaminated with fecal matter.

Then there are water-based diseases, which differ from waterborne diseases in that they are caused by parasites living in the water. Humans contract water-based diseases when parasites are ingested or come in contact with skin. These diseases most often result in intestinal worm diseases that impair cognitive function and reduce physical growth and fitness (Gleick et al., 2011: p.58). Gleick et al. (2011) estimate that 133 million cases of worm parasites are discovered each year, with many more going undiagnosed. In addition, Zhang et al. (as cited in Gleick et al., 2011: p.58) suggest that schistosomiasis, a non-worm parasite, currently infects 160 million people and is responsible for 200,000 largely unnecessary deaths per year in sub-Saharan Africa alone.

Significant health problems are also associated with contaminated water that are not classified as diseases. High concentrations of naturally occurring contaminants such as arsenic and fluoride increase the risk of skin and cardiovascular diseases, as well as problems with cognitive development, and many forms of cancer (Kalimuthu and 
Hoassain, 2008; Mosler et al., 2011). Improperly managed agricultural processes produce runoff waters high in unnaturally occurring concentrations of nitrates and persistent organic pollutants. The potential health effects of nitrates and persistent organic pollutants are numerous and severe, including cancers, thyroid imbalances, birth defects, disruption of developmental functions and immune system problems leading to death (Gleick et al., 2011: p.58).

Other contaminants, mainly from industrial processes, often lead to high levels of metals in water. These waste metals can accumulate in fish species, in concentrationlevels thousands of times higher than the water itself. (Gleick et al., 2011: p.59). Hazardous levels of contaminants such as mercury, lead and zinc manifest in humans through the food chain. The effects of unhealthy exposure to metals have been demonstrated to cause chronic health effects, including heart disease, development and neurological damage, cancers, brain damage and blood disorders (Gleick et al., 2011: p.60). The presence of these contaminants and their links to the food chain underscore the latent effects of contaminated water.

For populations facing water scarcity, improving access to clean water will significantly decrease these numerous health risks, provided they can access the water in sufficient quantities. International health standards recommend a minimum of 50 litres of water per person per day to satisfy adequate drinking, cooking, washing and sanitation needs (Caso, 2010: p.8). Many water-stressed countries have less than half of this amount available for the vast majority of the population. Home and municipal use of water varies geographically and based on ease of availability. In the United States (US), the average daily per capita freshwater usage is 193 liters; in Ethiopia, this figure is 11.6 liters (Caso, 
2010: p.5). As human and industrial demands for water increase, less water is available per person, and countries that already have scarce water supply find themselves in a critical state. Accounting for population growth and lowered availability of freshwater, Clarke and King (2004) predict that by 2050, more than 4 billion people will live in water-stressed conditions, with the vast majority in developing regions.

It is estimated that 84 percent of the world population without a safe drinkingwater source lives in rural areas (WHO/UNICEF JMP, 2010). For the majority of these rural populations, the dominant sources of improved water are located great distances from dwellings, requiring extended amounts of time for travel and collection (WHO/UNICEF JMP, 2010). Time spent collecting water has been shown to be a determinant of meeting the recommended minimum water per person per day. For example, studies in several countries within Sub-Saharan Africa have reported that it is common for it to upwards of 30 minutes per round trip to collect water from a safe source (Davis et al., 2008; Hutton and Haller, 2004). In these instances, it is estimated that 25 percent of the population spend more than 30 minutes per round trip to collect water, often multiple times a day. In urban settings where prevalence of piped sources is statistically higher, it is estimated that roughly 40 percent of the population still spends more than 30 minutes per round trip to collect water from an improved source sometimes several times daily (WHO/UNICEF JMP, 2012).

Lacking access to nearby freshwater results in considerable hardship for those who have to travel great distances to obtain it, which is most often assigned to women and girls (WHO/UNICEF JMP, 2010). Tandon (2007) estimates women and girls commonly spend upwards of eight hours a day traveling by foot to the nearest water 
source, while carrying up to 20 liters of water on the return trip. This is time that women could devote to other pursuits such as education or economic activity that might help to alleviate poverty of their families. Nakagawa (2009) estimates that the time lost to women obtaining water amounts to roughly 20 billion working days per year, or the equivalent of approximately $\$ 63$ billion USD, if that time was spent working instead.

Research into the health effects of time spent collecting water has found that the greater the amount of time required to collect water, the less water is actually collected, and the higher the likelihood the water becomes contaminated (Davis et al., 2008; Hutton and Haller, 2004). Specifically, as the quantity of water collected decreases, the greater the likelihood individuals will recycle the water, increasing the chance of contamination, especially in cases when sanitation is not a common practice.

These challenges tend to fall disproportionately on the poor as they strive to lead healthier lives and to be more economically productive. It follows that those with the least access to water and sanitation are also the least likely to have access to healthcare and stable employment. Water-related illnesses further reduce income or the potential to obtain income through work and, for the most vulnerable, can lead to death. As such, disparities in water access between the richest and poorest percentages of a population exacerbate the struggle of the poor for a better life.

Another significant reality faced by the poorest is the disproportionate amount of their income needed to the purchase water. Whereas the average US citizen will spend an average of 0.006 percent of annual income on water, an average Tanzanian citizen will spend 5.7 percent (Clarke \& King, 2004). In the context of developing countries, the poorest pay the most for water and use the least. In urban areas the poor often cannot 
afford to have water piped to their home, whereas piped water services are rarely available in rural settings.

As a result, the poor must resort to buying water by the container at highly inflated prices from unregulated water vendors. In Manila, Philippines, in 1997, 1 cubic meter of piped water cost $\$ 0.11$ USD, while the same quantity purchased through water vendors ran a cost of \$4.74 USD (Clarke \& King, 2004). When considered in terms of proportion of income, it becomes apparent the poor will use considerably less water, and as a result, are more prone to the effects of contamination.

Examining these disparities further, a gender lens provides additional insight towards one of the most significant differences related to water: the role of women. The lives of women without access to water are vastly different and disadvantaged than those fortunate enough to have improved access. It is estimated that women make up 70 percent of the poor population worldwide and, as a result, make up a considerable proportion of the 780 million people without access to water worldwide (Tandon, 2007).

Because women are the primary caregivers in many cultures, when contaminated water affects the health of water-stressed populations, it puts additional strain on women who care for ill family members in addition to their everyday duties (Gleick et al., 2011). Conversely, when women become ill from contamination, these risks are transferred to their families as young children or elderly family members may not receive the care needed and typically provided by women.

These problems are exacerbated since obtaining and domestically managing water is commonly a primary responsibility of women, they are more likely to come into contact with contaminated water. In addition, due to the great amounts of time spent 
collecting water when not available locally, women and girls often miss out on opportunities to gain an education, which is necessary to improve hygiene and sanitation for their families and communities (Tandon, 2007; Gleick et al., 2011).

The need for separate toilet facilities for women and girls is often neglected, commonly resulting in absenteeism from work or school. Moreover, a lack of safe and private sanitation facilities for women and girls can put many at risk of assault or rape when forced to seek out secluded places for privacy (Gleick et al., 2011). Numerous reports and studies indicate that when separate toilet facilities for girls are put into schools, the attendance rate of girls increases dramatically (Taylor, 2011; Gleick, 2005).

Children in general, are by far the most disadvantaged population concerning issues of water and sanitation, suffering an overwhelming majority of the deaths relating from water-related diseases. Children under five years old are at the greatest risk of mortality, as unsafe water and poor sanitation are responsible for eighteen percent of under-age-five deaths in developing countries (Gleick et al., 2011, p. 61). For those children who do not succumb to water-related illness, there remain many barriers to healthy physical and cognitive development for children living in water-stressed conditions. The aforementioned water-related and water-borne diseases risk impairing children's abilities to gain adequate nutrition and for the healthy development necessary to succeed in school and life. The UN estimates that every year, 443 million school days are lost for children suffering from water-related diseases (Gleick et al., 2011, p. 62).

Setting goals for development in these areas is an important step towards focusing attention and mobilizing action on these crippling water-related challenges that primarily affect the developing world. This is why, in the year 2000, the UN along with many 
leading international development organizations and heads of state from 189 countries met to discuss ways to end poverty and inequality in developing countries. The result set in motion the Millennium Development Goals (MDGs), which were announced in 2001, setting eight broad objectives to be achieved through international development efforts, by the target date of 2015 .

The MDGs consist of eight far-reaching goals for improving conditions related to poverty, health, child and maternal mortality, education, gender equality, environmental sustainability, as well as political and economic development. The MDGs implicitly recognize that ending poverty and inequality, improving health, and providing greater economic opportunities for the world's poorest and most disadvantaged begins with meeting basic needs for clean water and sanitation. Although only one goal is directly related to water, specifically goal $7 \mathrm{C}$, access to water and sanitation are implicitly tied to the achievement of all the other goals ${ }^{1}$. Target $7 \mathrm{C}$ of the MDGs aims to reduce by half the proportion of people without sustainable access to water and sanitation.

The Joint Monitoring Programme (JMP) report (WHO/UNICEF JMP, 2012), a joint effort on behalf of UNICEF and the WHO, reports every two years on progress towards target 7C. The most recent JMP report indicates the world is behind schedule meeting this target as 780 million people lack access to water and 2.5 billion lack improved sanitation. ${ }^{2}$

\footnotetext{
${ }^{1}$ See Appendix A for detailed breakdown of the seven Millennium Development Goals and the importance of water and sanitation towards accelerating efforts for each of the goals.

${ }^{2}$ It is important to note that the JMP data is measured based on availability of access and relative proximity to known water and sanitation facilities. The definition used in the methodology does not take into account whether the facilities are in working condition, nor does it account for the risk of contamination due to water from contaminated sources or improperly maintained sanitation facilities (cf. WHO/UNICEF JMP, 2012. P. 34).
} 
The JMP (WHO/UNICEF JMP, 2012) measures water access in terms of three categories: improved water sources, other improved water sources and unimproved water sources. Improved sources must be piped to a household connection located inside an occupied dwelling yard, which is particularly difficult for rural populations. Failing to achieve this, other improved water sources are sources of a shared nature that have some means to protect water from contamination, such as public taps or standpipes, tube wells or boreholes, protected dug wells, protected springs or rainfall collection. The JMP considers any other sources as unimproved, as they provide no protection against contamination.

According to the latest JMP report (WHO/UNICEF JMP, 2012), 87 percent of the global population is considered to have access to an improved water source. The remaining 13 percent of the global population, or 780 million people, the majority of whom are from developing regions, attain water from unprotected sources which typically include unprotected dug wells, unprotected springs, or surface water from rivers, dams, lakes, ponds and sometimes even puddles.

Access to improved sanitation remains an even greater challenge, particularly in developing regions. According to the JMP report (WHO/UNICEF JMP, 2012), to classify under improved sanitation, facilities must ensure hygienic separation of human feces. from human contact through piped sewer systems, septic tanks or specific types of pit latrines. Conversely, unimproved sanitation facilities are considered anything that does not ensure hygienic separation of human excreta from human contact, which commonly includes pit latrines without a slab or platform, hanging latrines, bucket latrines and any sanitation facilities shared between households (WHO/UNICEF JMP, 2010). 
Globally, 61 percent of the population has access to improved sanitation facilities. This means roughly 39 percent, or 2.5 billion people, are classified as having unimproved facilities or practicing open defecation (WHO/UNICEF JMP, 2012). Open defecation is the remaining and most dangerous classification for sanitation, which consists of actions whereby human feces are disposed of in fields, forests, bushes, open bodies of water and other open spaces or when it is disposed of with other solid waste (JMP, 2010). Open defecation poses an extremely high level of risk to human health and the quality of nearby bodies of water. The JMP (WHO/UNICEF JMP, 2012) estimates more than half of the populations of South- and Eastern-Asia, as well as Sub-Saharan Africa are without improved sanitation with open defecation the most prevalent method in rural settings.

According to Hutton and Haller (2004), an investment of \$11.3 billion USD per year is needed to meet the water and sanitation target of the Millennium Development Goals, which would generate a total return on investment of $\$ 84$ billion USD a year. It is estimated that for every US dollar invested in sanitation and drinking water improvement, there is a projected return of $\$ 3$ to $\$ 34$ USD in corresponding economic development (WHO and UN-Water, 2010). Globally, the poor and marginalized are affected by poor health, limited educational and economic outcomes that are often directly associated with inadequate water quality and improper sanitation. Investments in water supply, sanitation and hygiene will generate economic, environmental and social benefits by reducing health risks and freeing-up time for education and other productive activities. Healthier and better-educated populations improve the economic opportunities of these disadvantaged populations while also increasing the strength of the domestic labour force, increasing the potential for GDP growth of each affected nation. Overall, there is 
much to be gained by bringing the benefits of improved water and sanitation practices to those who lack it.

Conversely, countries with poor water quality also experience numerous economic forfeitures. Damage to ecosystems, decreased productivity of agricultural and industrial sectors, loss of tourism and decreased health of human populations, all carry economic costs that can be directly associated with poor water quality and lack of improved sanitation (Gleick et al., 2011, p. 63). Poor water quality is a significant detriment to the health of human populations, as it contributes to loss of productivity, higher costs of healthcare and treatment of those with water-related illness and economic losses as a result of increased mortality (Gleick et al., 2011, p. 63).

Freshwater and improved sanitation are integral to the completion of all of the other MDGs, in addition to being central to economic growth, social stability and the reduction of poverty worldwide. Clean water is the base upon which many other development opportunities become possible with improved access to water and sanitation opening possibilities for immediate and long-term benefits. Improving the health, education and economic opportunities of current populations can empower the current generation to raise the next generation without the same level of poverty. Promotion of greater access to water and sanitation should, therefore, be prioritized as one of the most effective efforts towards improving the living conditions of the most disadvantaged populations worldwide.

Initiatives addressing the importance of improving access to water, sanitation and hygiene are prominent throughout developing countries. Development programmes focusing on these interrelated challenges are commonly referred to as WASH 
programmes, standing for Water Access, Sanitation and Hygiene. As such, WASH

programmes are the subject of the next chapter where they will be discussed in greater detail. 


\section{Chapter: The Sustainability Crisis}

As introduced in the previous chapter, programmes and initiatives focusing on the interrelated components of water access, sanitation and hygiene (WASH) offer a potential solution to the difficult realities of those with insufficient water and sanitation. In large part due to WASH and similar programmes, more than 2 billion people have gained access to improved drinking water sources and 1.8 billion have gained access to improved sanitation facilities since 1990 (WHO/UNICEF JMP, 2012). To explore how this has been accomplished, this chapter provides a general overview and historical perspective of how WASH programmes improve the water and sanitation conditions of communities around the world, as well as an overview of the current challenges facing these programmes with concrete examples.

WASH programmes exist, in large part, due to the benefits of combining sanitation and hygiene with water access-related initiatives. This is because, combining efforts to improve sanitation with water access is far more effective at stopping the spread of waterborne diseases than is access to water alone, which previous to WASH, had been the dominant approach. Whereas, the availability of safe drinking water is important, improvements to sanitation and hygiene practices are more so because they reduce the risk of water becoming contaminated, and individuals infecting themselves.

As demonstrated in chapter one, the Joint Monitoring Report (JMP) (WHO/UNICEF JMP, 2012) estimates 780 million people, the majority of which are rural populations from developing countries, endure a precarious relationship with water, attaining their water from water vendors at highly inflated prices, or forced to rely on possibly contaminated water sources such as ponds, lakes, rivers or puddles at potentially 
great distances from their dwelling. In addition, 2.5 billion people continue to live in conditions with poor hygiene and inadequate sanitation, where open defecation is common and opportunities for hygienic practices such as hand-washing at critical times ${ }^{3}$ is rare.

Before proceeding, it is important to provide definitions for the terms "hygiene" and "sanitation" as different programmes tend to use different definitions. This discussion employs the definition used by Peal et al. (2010), who define sanitation as the management and treatment of human excreta to avoid contact with humans, and hygiene as the proper actions required to limit or stop the transmission of infection in the home or community.

Individuals and, particularly, communities that do not practice proper sanitation and hygiene are at a high risk of contaminating clean water sources, as awareness of how sickness is transmitted is not well understood in many developing regions ${ }^{4}$. Numerous studies have reported that individuals do not understand that microscopic contaminants, invisible to the naked eye, are present in water that appears clear (Davis et al., 2008; Levison, 2010). Furthermore, despite these risks associated with visually clear water, many populations are accustomed to drinking murky and cloudy water with visible particulate (Levison, 2010). This common misconception underscores why hygiene

\footnotetext{
${ }^{3}$ Programmes with hygiene education components often teach and promote hand-washing at critical times following potentially hazardous activities. In its terms of reference for implementation of a WASH programme in Bangladesh (SHEWA-B), UNICEF defines six critical times for hand-washing (always with soap or ash) as after defecation, before serving/cooking food, before feeding children, before eating, after cleaning an infant's bottom and after disposing of children's feces (IRC International Water and Sanitation Centre and WaterAid, 2008).

${ }^{4}$ In Tanzania, for example, the symptoms of malaria are often misdiagnosed as degedege, an evil bird that flies over children trying to get inside them, which is commonly treated by traditional healers (Makemba, et al., 1996). Epstein likens this to the "miasma" theory of teenth century England (Epstien, 2007).
} 
education is so important to dispelling the myths and beliefs associated with the unimproved water and sanitation practices.

Another challenge with drinking water is how it is used and stored. For the majority of households without a piped water connection, water is stored in large containers where it can be later used for cooking and drinking. Deterioration of water quality often occurs when individuals dip contaminated hands, cups or utensils into the containers risking the transfer of pathogens to the entire quantity of stored water. Davis et al., (2008) consider domestic water storage as one of the primary contamination points as clean water often becomes contaminated unnecessarily due to improper storage as it is used and recycled for different purposes. In addition to improved water access, improved sanitation and knowledge of hygiene better enables communities to avoid contamination of their water sources, which in turn improves water access and the overall effectiveness of WASH interventions.

Reports from the World Health Organization (WHO) and the United Nations Children's Fund (UNICEF), as well as numerous other reports on the subject, advocate sanitation and hygiene education as significantly more effective at reducing diarrheal disease than improved water access alone (Bartram and Caimcross, 2010; OECD, 2011; WHO/UNICEF JMP, 2010; WHO/UNICEF JMP, 2012). In communities without proper sanitation facilities, diarrheal diseases account for the majority of illnesses and, higher than average rates of fatality. The World Bank (2010) considers diarrheal disease prevention through hygiene and sanitation promotion its top disease control priority, citing upwards of 400 child deaths prevented by each $\$ 1000$ USD invested in WASH programmes. 
This is why WASH programmes generally include measures to improve access to water and improved sanitation by providing the necessary infrastructural components and supplies, as well as hygiene awareness and education. As such, key components of WASH programmes consist of providing access to clean water and stopping the fecaloral transmission of germs ${ }^{5}$ by improving the hygienic practices to reduce the risk of infections and further contamination of water (Davis et al., 2008; Peal et al., 2010). WASH programming has grown into a worldwide movement with support of governments, nongovernmental organizations (NGOs), aid organizations, donors and other third party partners. For example, in 2010, UNICEF, the largest support agency in the water and sanitation sector, funded WASH activities in 106 countries providing $\$ 393$ million USD (UNICEF, 2011). Countless other organizations, groups and countries are also delivering or partnering on WASH programmes in almost all developing global regions. It is estimated that in the 1990 s, annual investment by governments and aid organizations in water access and sanitation in developing countries totaled $\$ 15.7$ billion USD (Hutton and Bartram, 2008).

The history of WASH initiatives dates to the late 1960s, when the WHO piloted development efforts targeting water and sanitation in an effort that later developed into creation of the International Water and Sanitation Centre (IRC). It was not until much later, in the 1980s, that the WASH acronym was coined by the United States Agency for International Development (USAID). During the 1990s a number of organizations began

${ }^{5}$ Consumption of contaminated water is the main cause of water-related and water-borne diseases, however, the fecal-oral transmission of pathogens remains a considerable risk, underscoring the importance of improved sanitation and hygiene practices as a means of preventing further transmission of germs(Curtis \& Cairncross, 2003).

See Appendix B for a diagram of the fecal-oral transmission of germs and ways to break the transmission route. 
focusing on water and WASH issues with many approaches and standards for the sector being developed. In the early 2000 s, considerable emphasis was placed on WASH programmes following recognition from the United Nations Children's Fund (UNICEF) and the Water Supply and Sanitation Collaborative Council (WSSC) that WASH programmes could accelerate achievement of the Millennium Development Goals (MDGs) target for water and sanitation.

WASH programmes represent a genus of development programming, rather than a specific replicable model. Although there are many general similarities, most WASH programmes are implemented differently, as variations of programming have been developed from the numerous implementing organizations, and applied differently throughout many developing countries and regions respecting changes in geographic and cultural needs. That said, most WASH programmes follow a similar design, which includes planning, implementation and, to varying extents, follow-up components. They are generally implemented by not-for-profit or non-governmental organizations (NGOs), or sometimes as national programmes instituted in partnership with NGOs and governments of developing countries ${ }^{6}$. In addition, many include partnerships and engagement with other stakeholders and supporting agencies, local groups or various levels of government (Adhikari \& Lal Shrestha, 2008; Peal et al., 2010).

\footnotetext{
${ }^{6}$ Peal et al (2010) list the following programmes as types of WASH programmes that have been deployed over the past two decades: Community Health Clubs (CHC), Environmental Health Project (EHP), Hygiene Improvement Framework (HIF), Total Sanitation Campaign (TSC) and School Led Total Sanitation (SLTS), Hygiene Improvement Project (HIP), Household Centered Environmental Sanitation Approach, Child Hygiene and Sanitation Transformation, and Global Scaling-Up Handwashing Behaviour Change Project (GSUHBCP) just to name a few of the numerous variations of WASH programmes.
} 
The preparation and planning phase often involves the selection of key participants and the establishment of groups that help disseminate programme messaging and spread awareness of key WASH messages. Many programmes integrate a component of needs analysis into the planning phase. This is used to determine the scale required for facilities and to identify key concerns and priorities of the target population as well as identification of hazardous activities that must be halted. For example, in communities where open defecation is common "No Open Defecation Villages" are often determined as a goal for implementation, followed by emphasis on promoting awareness of improved sanitation and hygiene activities.

After the initial planning is complete, the next step for WASH programmes is typically implementation, where practitioners work with villagers and local authorities to deliver programme components on-site. Implementation generally receives the most attention from NGOs, programme practitioners, funding bodies and other stakeholders. Commonly, implementation consists of constructing new facilities to access clean water and proper disposal of human waste, alongside promoting awareness and education of sanitation, such as the importance of hand-washing and how to use the provided facilities. Participants from the target population are trained to use and maintain the new facilities, as well as educated about the importance of proper sanitation and hygiene so that they may teach others in the community. This phase typically requires the greatest amount of human resources, as labourers are needed to construct the facilities and practitioners to educate the community and oversee the project.

Following the implementation, there is sometimes an additional stage consisting of some form of follow-up, where WASH practitioners may revisit communities or 
commission surveys to monitor and evaluate progress. Typically, the focus is on identifying needs for repairing or upgrading facilities, as well as assessing the percentage of the population who continue to employ the proper practices and use the new facilities (Adhikari \& Lal Shrestha, 2008; Peal et al., 2010). Follow-up components are not always performed, as budgetary and human resource limitations often limit the ability for practitioners to return to previous projects. In place of having the practitioners and programme implementers return, reporting will sometimes be carried out by members of the local community given responsibility with this task during the implementation process.

Finally, it is important to note that the delivery of WASH programmes is constantly evolving as new methods for programme delivery are developed to address the ongoing challenge of how to better enable people to gain access to water and sanitation facilities and to improve long-term adoption of hygienic activities. Despite tremendous investments and improvements in different implementation strategies, WASH initiatives frequently fail to realize long-term changes in the WASH-related activities of target communities. For varying reasons, encouraging target communities to adopt WASH practices remains a consistent and considerable challenge.

According to the latest Joint Monitoring Programme (JMP) report (WHO/UNICEF JMP, 2012), target 7C, the water and sanitation target of the MDGs, is off track globally and it is unlikely that the goal will be met by the end date of 2015 . The Secretary General of the United Nations, Ban Ki Moon, argues in a foreword to the JMP report, that "it is essential to accelerate progress in the remaining time before the MDG deadline" (WHO/UNICEF JMP, 2012). Although Moon considers that much has been 
achieved towards improving water and sanitation access, he recognizes that there remain many challenges and much more work to be done in order to not fall further behind.

Despite the considerable progress delivering water and sanitation access since 1990 , there remain 780 million people without access to improved water sources and 2.5 billion who continue to practice open defecation without improved sanitation (WHO/UNICEF JMP, 2012). At the global level, gains have only kept slightly above the pace of population growth, masking the diminished progress in the least developed global regions over this time period. Specifically, sub-Saharan Africa and Southern Asia are in jeopardy of falling behind population growth, risking a reversal of the progress and positive momentum gained by previous WASH programmes (WHO/UNICEF - JMP, 2012).

As it becomes increasingly apparent that the MDG target for water and sanitation is not going to be met, a case can be made that WASH, as an approach, is facing a crisis of sustainability as reports are finding high rates of programme failure. According to the Blue Planet Run Foundation (2012), roughly half of all WASH projects fail within 2-5 years of implementation. Water for People (2013) estimates up to 30 percent of water projects fail in the first few years. Peal et al. (2010) attribute the high rate of failure to the inability of programmes to enable sustained hygiene and sanitation activity changes of individuals, and subsequently activity changes among their communities as a collective. In other words, despite the WASH interventions, these individuals and communities are reverting to collecting water from unimproved sources and are reverting to the unimproved sanitation practices that subsequently increase the risk of water contamination. 
The literature on WASH offers a number of reasons for why programmes are not being continued long-term. Peal et al. (2010) argue that the fault lies not with the approach of WASH, but instead how it is usually planned and implemented. Others, such as Sugrue and Pfluger (2012), identify time and resource challenges, a common threat to every aid programme, as forcing programmes to pursue more modest and expedient solutions. Robinson (2005) considers that large numbers of WASH programmes fail because the water supply and facility development components generally consume the majority of program time and resources. In these instances the WASH activities are often reduced to mere water access or latrine building exercises, with hygiene and sanitation education added as an afterthought.

Breslin (2010) provides an example of this type of failure experienced in the community of Ché, Guatemala, which refused to work with his organization, Water for People, which intended to follow-up on a failed WASH programme ${ }^{7}$. According to Breslin (2010) the original programme was instituted by an unnamed NGO that built latrines for 30 families but ran out of funds to provide the remaining 35 families with latrines of their own. This shortfall was attributed to the initial latrines taking longer to construct than the NGO had originally estimated, largely as a result of inexperience in construction abroad. Upon expending all of its resources, the NGO left the latrine designs in the hands of the community, in English, and promised to return at a later date to complete the remainder.

\footnotetext{
${ }^{7}$ It is important to note the polemical nature of the example found in Breslin (2010), as it appears as a case study that supports his larger essay arguing for stronger reporting measures and greater transparency of NGOs, philanthropists and governments in the delivery of water and sanitation programmes.
} 
When Breslin and his organization, Water for People, approached the Ché community to complete the remaining latrines, the community rejected the proposal. Water for People offered to complete the remaining latrines provided the community agreed to partially fund the construction. The offer was structured this way because Water for People insists on financial contributions in all of its projects as a way of ensuring a sense of ownership for the constructed facilities and for the community to demonstrate the ability to cover the future operation and maintenance costs. Instead, the community refused on the basis that they expected the remaining latrines to be provided for free similar to the original programme.

Breslin (2010) argues that even if his organization or the original group had installed enough latrines for the entire community, this model is prone to fail because the community would have had the same expectation that future latrines will be provided when a new family joins, or is formed in the village. Breslin (2010) argues that programmes that are implemented in the form of charity breed dependency and as a result often lead to failure as communities do not understand the actual costs of installation, maintenance and repairs, and are not prepared to manage them.

Assuming programmes successfully manage time and resources, the failure to achieve long-term adoption of WASH-related practices remains a persistent barrier to generating sustained implementation of the improved practices. This is because, once infrastructure is built and education is provided, the new healthy practices frequently fail to be widely adopted and communities often revert to old habits, which may include open defecation, absence of hand-washing or drinking untreated water. 
Recurring themes in post-mortem reports and programme reviews indicate often unused, misused, abandoned or broken facilities coinciding with discontinued participation among the target communities (Breslin, 2010; Mosler, 2012; Peal et al., 2010). This is because once the programme practitioners have completed implementing the programme, the communities are left to manage and continue the practices on their own, frequently conflicting with the entrenched way of life of these populations.

In these instances, programmes are often considered to have achieved success too quickly. In many projects initially considered a success, the improved WASH-practices are not maintained once implementation has been completed and the programmes are handed over from the implementing groups to local authorities. MacDonald and Schwab (2010) contend a common practice among aid organizations is to complete implementation, and subsequently declare the programme a success without collecting any data to determine if the actions of the community have changed, if health has improved or without any plans for follow up support beyond much more than a year, if at all. Blue Planet Run Foundation (2006) estimates that less than five percent of projects are visited post-construction and less than one percent receive any long-term monitoring.

A concrete example of a similar type of failure can be found in a Community Led Total Sanitation (CLTS) programme from Malawi led by Engineers without Borders (EWB) in tandem with a partnered NGO (cf. Kennedy and Nilsson, 2012). The CLTS programme instituted by the two organizations comprises a community-based model, designed to target the entire community rather than parts of it. Community-based models

\footnotetext{
${ }^{8}$ This example appears as a case study in the annual Failure Reports from Engineers Without Borders (EWB) Canada. By highlighting and reporting failures as well as lessons learned in its affiliated activities, EWB hopes to share lessons more broadly so others may learn from the mistakes of these failed activities (Engineers Without Borders Canada, 2012).
} 
are believed to foster a sense of ownership by encouraging community members to design programme elements to best fit the practices of the community (International Water and Sanitation Centre, 2011; Peal et al., 2010). Peal et al. (2010) consider this approach representative of the current thinking in the water and sanitation sector, whereby inclusion of the whole community is essential towards changing the WASHrelated activities. Specific to CLTS programmes, the primary goals of providing sufficient quantity and quality of water are achieved through a system of targets that dictate the timeframe and completion of implementation before handing the programme over to local authorities.

Kennedy and Nilsson (2012) describe a CLTS programme in a rural village in Malawi that appeared quite successful throughout implementation only to fail immediately upon completion. Kennedy and Nilsson (2012) note that throughout implementation the community was happy and the CLTS targets were being met regularly and in abundance. As the targets were increasingly met, EWB aligned the necessary components to ensure a smooth transition to the local government upon completion of all targets. In consultation with community leaders, EWB trained government extension staff to conduct the CLTS activities and data collection processes required for follow-ups and oversight. Towards the end, a government official was appointed to the community, roles and responsibilities were mapped out, and a twomonth transition period was scheduled. The implementing NGO had planned, that at the end of this period the community would be certified as "open defecation free" and celebrations were to be held along with a Fanta soft drink to reward each member of the community. 
In the days leading up to the final celebration the programme began to experience problems. The village headman, upon discovering his village would not receive as elaborate a celebration as a neighbouring community with a different bigger-budget $\mathrm{NGO}$, told villagers to stop participating in the programme. In addition, it became apparent that the government official could not afford to continue to pay the same number of trained extension staff because the government budget was much less than the amount paid by the instituting NGO throughout the programme. Furthermore, the CLTS monitoring process could not continue, as the government could not afford the costs needed to collect forms in the manner established by EWB. With reduced staff, the time needed for data input was more than the time the government official could spare; who, Kennedy and Nilsson (2012) contend, was already running the CLTS from the side of his desk. Nonetheless, the CLTS targets had all been met and the celebration was held to reward community members and to mark the successful completion of the implementation phase of the programme.

The result of these numerous oversights was that the NGOs had created local expectations that far exceeded the limited resources available to the local government. Pressured to achieve results, EWB and the partner NGO failed to work within the constraints of the local government, making it impossible for the local government to effectively continue the CLTS programme post-implementation. Kennedy and Nilsson (2012) admit that by making the initial component of the programme work, the programme inadvertently created an artificial environment that the community and local government could not maintain, which resulted in the programme being unsustainable and the practices not being continued. 
Functioning water and sanitation facilities must be maintained against general wear and tear or, if necessary, replaced to ensure continued provision of the clean water or sanitary conditions necessary for populations to be able to continue the improved WASH practices. Given the frequent lack of follow-up, often there is no way to know if the improved practices are being continued or if facilities are functional. Unfortunately, the facilities provided through WASH programmes are commonly breaking down and evidence suggests communities rarely choose to repair them (International Institute for Environment and Development, 2009) ${ }^{9}$. For example, survey findings from Mali have found upwards of 80 percent of wells in the country are dysfunctional, whereas other surveys from Ghana have found 58 percent of water access points are in need of repairs (International Institute for Environment and Development, 2009). Based on similar surveys, the International Institute for Environment and Development (IIED, 2009) estimates there are over 50,000 broken rural water points across Africa alone. The IRC estimates that in the past two decades, between 600,000 and 800,000 hand-pumps have been installed in sub-Saharan Africa, with upwards of 30 percent known to have failed prematurely, representing a failed investment of more than $\$ 1.2$ billion USD in hardware alone (International Water and Sanitation Centre, 2009).

Reporting of these challenges presents another challenge as poor, falsified or nonexistent data collection renders it difficult to ascertain reliable data on project outcomes.

\footnotetext{
${ }^{9}$ It should be noted that while this is specifically in reference to facilities, usually sanitationrelated, that are not repaired when broken or in need of significant repairs. Water sources that break, on the other hand, are often not repaired for other reasons, such as the perception that the source is not needed due to the availability of water elsewhere, or the inability for the community to afford repairs (which may also include the inability for the community to organize sufficient funds to pay for the repairs), or if the repairs can be afforded, because there is no local capacity to provide the repairs.
} 
For example, a study of northern Mozambique found government data vastly overestimated improved water access at 72 percent, when the study found actual coverage for the region was closer to 21 percent (Breslin, 2010). Other reports on WASH programmes denote a lack of proper data collection and note attaining reliable data is a significant challenge throughout the sector (UNESCO, 2006; WHO/UNICEF JMP, 2012; Saboori et al., 2011; Tamas and Mosler, 2011; USAID, 2010; Breslin, 2010). Unreliable data conceals and underestimates the magnitude of the water crisis, while inaccurate reporting of the success of WASH programmes masks and deceives the sector as a whole.

WASH in Schools is an example of a programme intended to improve on this lack of data in the sector. WASH in Schools consists of a joint UNICEF and World Water and Sanitation Council (WSSCC) initiative based on the WASH platform. WASH in Schools promotes measures to improve access to water and sanitation by provisioning water and sanitation facilities alongside education about hygiene through the existing primary school network in the countries where implemented. This approach recognizes how school children, educated to the benefits of sanitation and good hygiene, carry these practices beyond the school walls, potentially spreading the WASH messaging to their families and communities.

Saboori et al. (2011) illustrate the results of a follow-up evaluation of an initially successful WASH in Schools pilot programme implemented across 60 communities in Nyanza Province, Kenya ${ }^{10}$. The programme consisted of a typical WASH in Schools

\footnotetext{
${ }^{10}$ The example offered by Saboori et al. (2011) is an evaluation report of a WASH in Schools pilot programme in Nyanza Province, Kenya, conducted 2.5 years after programme implementation. The report has a somewhat polemical nature given the authors are applying the findings to propose an enabling environment approach for future implementation of WASH programmes in schools. It is also important to note that the authors consider their evaluation to be
} 
initiative ensuring clean water, sanitation facilities and hygiene education to primary school students. The pilot programme provided each school with point-of-use drinking water treatment to ensure clean water for drinking and sanitation, water storage containers for safe water storage and hygiene educators to train the teachers and oversee the programme for one month. In addition, the programme instituted "school health clubs" $" 11$ for each school and tailored messages for students to transfer to their parents to encourage parental and community involvement.

The follow-up evaluations were conducted two and half years after the initiatives were handed over to local authorities, collecting data from 55 of the 60 originally participating schools. Targets for success stipulated that schools in which the practices had been sustained would carry out each of the improved activities, such as having available drinking water in storage containers, uncontaminated water treated with chlorine and the availability of water and soap for hand-washing. Survey results found none of the 55 participating schools had maintained all of the WASH interventions, and 25 schools did not have any of the components in place, despite numerous schools falsely reporting that they had been.

The researchers then set out to find what went wrong and what went right. Investigating reasons for these failures, Saboori et al. (2011) identified a number of barriers to programme success. Most of the schools reported breakage of the safe storage containers, which resulted in the inability to store or treat water. Only six schools actively

the first evaluation report on WASH in Schools as they are unaware of other evaluation reports on WASH in Schools already conducted.

${ }^{11}$ School health clubs are generally groups of students who are assigned responsibility for overseeing the upkeep of hygiene activities within the school. Responsibilities tend to include promoting hygiene and sanitation activities, ensuring the provision of soap, fetching and treating water as required and cleaning the sanitation facilities. 
replaced or repaired the containers as needed, while the remaining schools frequently reported not knowing where to get repairs or replacement parts or cited the costs associated with repairs prohibitive.

The participating schools saw the repurchasing of water treatment products, such as chlorine or soap, to be a substantial barrier to sustaining the improved practices. Roughly half of the schools did not allocate any funds for provision of soap or chlorine beyond the initial free supply. This resulted in the available water often going untreated and susceptible to contamination, whereas failing to provide soap resulted in a decline in hand-washing. A large proportion of schools cited unavailability of funds for these recurring costs as the most significant barrier to their continuation.

Lack of leadership within the school also presented a challenge for many schools. Turnover of teachers, which is common in Kenyan public schools, resulted in the programme-trained teachers departing the schools. The evaluations found only 22 schools reported having both the original trained teachers at the school, while 15 schools had none. As new teachers would enter the school they were not always trained in the WASH activities, and often lacked the same level of commitment as the teachers who participated in the launch of the programme. Without the trained teachers overseeing and coordinating the continuation of hygiene education and Health Clubs, the emphasis on the improved practices declined.

Saboori et al. (2011) identified two schools as the most successful as they met three of the four requirements for sustainability. Looking at what went right, these schools were then compared to determine similarities. Saboori et al. (2011) found that both schools reported repurchasing water treatment products, training new teachers, 
setting aside funds for recurring costs and carrying out WASH activities, such as building latrines, in the local communities. In addition, both schools statistically monitored the health of students and cited observed health benefits as one of the key factors contributing to continuation of the WASH activities.

Overall, the pilot programme was a failure for the vast majority of the 60 schools, despite the initial appearance of success. Ultimately, the pilot programmes were unable to sustain the improved activities in the years following the end of the implementation period. In addition, other evidence is beginning to surface suggesting WASH in Schools has, overall, not been very successful at encouraging adoption of the improved WASH activities. A UNICEF (2011) study conducted among sixty countries participating in WASH in Schools has found only half of the countries are tracking data on programme coverage, and among those countries, less than half of all primary schools are providing safe water and or adequate sanitation. The report further noted the current status of WASH in Schools programmes consists of facilities that, if they exist, are often in poor and unmaintained conditions, lacking the necessary water decontamination supplies, while education of hygienic practices is almost non-existent. As a result, it has become generally recognized that targeting only students and the schools is not sufficient to mobilize the improved practices throughout the entire community (International Water and Sanitation Centre, 2011; Pokharel, 2012; Saboori et al., 2011).

Saboori et al. (2011) concluded that failure to continue the improved activities was caused by weakness in one or more domains of support such as financial capacity, accountability, technical feasibility, school leadership and management, or student engagement; collaboration among these domains is necessary to ensure an enabling 
environment in the entire community. Saboori et al. (2011) recommend that, going forward, implementing organizations should ensure that all necessary elements are in place and well established prior to handing programme authority to the local community. The recommendations include ensuring the community has the necessary knowledge and ability to finance repairs should any of the facilities become non-functional.

In light of the above findings and examples, it is difficult to argue how WASH programming, as a whole, is a success. Although it is important to recall the importance and benefits of delivering sanitation alongside water access, something is happening to WASH programmes resulting in individuals and, to a larger extent, communities failing to adopt the improved WASH practices. Encouraging target communities to adopt WASH practices has always been, and remains, a considerable challenge. The UN Millennium Project report (United Nations Development Programme, 2005) urges greater efforts to drive demand for sanitation improvements and ways to influence activity change as a solution to more effective WASH programmes.

Influencing long-term activity change is the real challenge, as the provision of facilities or encouraging the replacement of the previous activities with improved WASH practices is not sufficient. Long-term success requires that individuals choose to use the clean water source and improved sanitation facilities in a self-sufficient manner indefinitely. In order to not fall behind population growth and to, perhaps, salvage any remaining possibility of meeting the MDG for water and sanitation, the water and sanitation sector will need to overcome these aforementioned challenges. The sector cannot afford such a high rate of programme failure. 
Since its inception, WASH programmes have progressed greatly in providing clean water, sanitation facilities and encouraging hygienic practices, as well as bringing increased attention to the importance of water and sanitation. The water and sanitation sector has continually changed the way WASH programmes are implemented, based on the assumption it will be possible to achieve better results with certain tweaks. Conversely, the three examples described above demonstrate that no matter the innovations and improvements, programmes are still failing to encourage long-term adoption of improved practices. Instead, they appear to be perpetuating the same challenges without addressing the root causes of why programmes are failing to achieve long-term activity change.

At its core, the success of WASH programmes is dependent upon the ability to facilitate long-term adoption of WASH-related actions by individuals and their communities. If communities are able to see the long-term benefits of improvements to their health, livelihoods and the subsequent wellbeing of future generations, demand for the maintenance of the provided-facilities may increase and ensure communities choose to continue the improved activities. As programmes are continually failing to achieve this, it is evident that something in the equation remains missing.

Evidence suggests that the current situation does not reflect this ideal scenario. The aforementioned reports and studies offer numerous reasons for this failure, yet programmes continue to fall short of projected goals with no compelling explanations. Instead, the answer may lie, implicit, inchoate and ignored, in these very studies and reports. Perhaps, what these studies provide is a set of theoretical components without a framework or model for future studies to follow and test. As such, the next chapter will 
attempt to identify and explicate a theory implicit in the reports on WASH by applying the theory in light of the examples discussed in this chapter, followed by an evaluation of the efficacy and usefulness of the theory in chapter five. 


\section{Chapter: A Theory for WASH}

As demonstrated in the previous chapter, WASH programmes are the key to delivering on the water and sanitation targets of the Millennium Development Goals (MDGs) and represent a massive global initiative that cannot afford to fail, yet estimates suggest that upwards of half fail (Blue Planet Run Foundation, 2006; Water for People, 2013). Post-mortem analyses and reports tend to be ad-hoc in nature, listing factors and causes for why individual programmes fail, but lack any linking context or theory (cf. Tamas and Mosler, 2011; Saboori et al., 2011; Pokharel, 2012; Breslin, 2010; Kennedy \& Nilsson, 2012). As such, exploring and identifying a theory implicit in reports on WASH is an important next step. This chapter will explicate a theoretical framework that facilitates greater understanding of the reasons why WASH programmes fail. Following this, chapter 4 will re-contextualize why programmes fail in order to better understand how they can succeed.

The success of WASH programmes depends on the ability to facilitate sustained changes in sanitation, hygiene and water treatment activities. The core of WASH programmes consists of introducing a new set of prescribed water-related practices to communities who are expected to adopt and continue long-term. Counter to the new rules and practices, on the other hand, are the long-standing activities already satisfying the water and sanitation needs of each community. Despite promises of reduced sickness, healthier children and better lives, communities consistently fail to maintain the WASH facilities or continue the WASH-related practices. The answer may, instead, be found by understanding how societies attain stability, how change happens over time and how society and change affect human activity. 
According to Harris (1979), societies may be considered relatively stable systems comprised of various interrelated components that seek stability and resist change. When the system is stable, the components are predisposed to resist most forms of change, as variation in one component of the system renders the system less efficient by straining the other components. Harris (1979) suggests the original components are pre-disposed to resist change in order to preserve the stability and efficiency of the system.

According to Harris (1979), social systems achieve stability by aligning the needs of society with the needs of individuals. Societies have a need to survive, which is chiefly accomplished by ensuring the population is replaced with future generations. Similarly, individuals have a need to survive and Harris $(1979$, p. 63) proposes that we achieve stability by meeting four general biological and psychological needs (cf. Maslow, 1954). The first of these needs is the need to eat which compels tendencies towards diets that offer more calories, proteins and nutrients when available. Second, Harris (1979) suggests we cannot be totally inactive, but when given the opportunity, we prefer to carry out tasks by expending a minimal amount of energy. These two needs suggest why humans act to maximize their energy potential by eating more when available and conserving energy when possible.

The remaining biological and psychological needs relate to how we are driven to reproduce and live socially. Harris (1979) suggests a third human need is for sexual intercourse, from which humans generally find reinforcing pleasure. Fourth, Harris (1979) suggests humans need love and affection in order to feel secure and happy, and we will act in ways to increase the affection that others give. Methods to satisfy these four needs are limited by the ecology where the society is based. Harris (1979) suggests how 
individuals make rational decisions in these systems about the costs and benefits of their actions within the limitations of the environment. Culturally approved methods of satisfying these needs then emerge in the form of the choices individuals make, which is done in a manner compatible with the ecology and geography of the society.

When WASH programmes are introduced in a target community, a relatively stable social system exists that already meets the biological and psychological needs of the society. It then follows that programme efforts to change the WASH-related practices of the population are met by resistance from other components of the system. In other words, individuals already have existing routines related to sanitation and hygiene supported by other long-standing components that satisfy other societal needs. Expecting the WASH-related practices to be continued long-term does not consider the various interrelated components encouraging reversion to the previous activities. As long as the other supporting components of the social system remain unchanged, it will be difficult to maintain the WASH-related practices. This line of thought is somewhat present in reports on WASH programmes, possibly helping to contextualize why communities frequently revert to previous practices, but is not made explicit in a social sense. Specifically, considering target communities analogous to a system is am important component in explaining why the long-term acceptance of WASH practices remains a considerable barrier to success.

The value emphasis ${ }^{12}$ of society is one such component of the system that will need to change in order to reflect the improved WASH-related activities. According to Harris (1979) the values of society are grounded in its needs, which are based on its

\footnotetext{
${ }^{12}$ Value emphasis refers to how different cultures place greater importance on different culturally defined standards (cf. Durkheim, 1948; Pareto, 1966; Parsons, 1968).
} 
social and physical reality. The value emphasis emerges as a way to best meet the needs of society. To paraphrase Williams (1970), values are abstract general standards of desirable states of affairs that serve as criteria for preference of choice or as justifications for proposed or actual activity. Values are emphasized differently in different cultures. Since different cultures find different ways to satisfy societal needs, it follows that societies place greater emphasis on those values that best satisfy the needs of the whole. The choices individuals make are based on the value emphasis of the social system, which aligns the needs of the system with the biological and psychological needs of its constituent members (cf. Harris, 1979; Pareto, 1966).

Value emphasis creates and aligns the shared norms ${ }^{13}$ and beliefs with what is best for society as a whole. All cultures and societies share the same values, and what distinguishes one society from another is the different emphasis they place on values (cf. Pareto, 1966). Durkheim (1933) referred to this as "value consensus", which represents the shared set of values a society constructs to meet the survival needs of the social system. The shared values of society allow order to be maintained and to define rules for social life. Similarly, Parsons (1968) argued social order is attained through society's commitment to common values by performing an integrating role between balancing the needs of society, while avoiding internal conflict. Parsons (1968) maintained norms and beliefs become part of motivation through shared values among members of society. Accordingly, value emphasis leads to norms that enable individuals to decide courses of

\footnotetext{
${ }^{13}$ Parsons (1968) describes norms as an extension of the value emphasis of social systems, serving as rules and expectations that reflect societal values, and implemented to ensure uniformity amongst members. Williams (1967) offers a similar account, suggesting norms represent the more specific, concrete and situation-bound specifications of actions judged in terms of the value emphasis of society. Norms are implicit regulations lacking the formal status of rules, yet manifesting just as subjectively and objectively real (Babbie, 1994).
} 
action, to explain and justify those actions and provide the necessary criteria to judge what is desirable from undesirable. In the context of WASH programmes, this lends to a consideration that if communities were to place a greater emphasis on proper sanitation and clean water, it is likely norms and beliefs will emerge to ensure these activities will be continued after the implementation of the WASH programme.

Harris (1966) illustrates how these concepts are intertwined in his explanation of how cows became sacred in India. He theorized that cows were not always considered holy in India, and that the worshipping of cows evolved slowly in order to satisfy the needs of the society in the face of environmental limitations. Over time, the value emphasis of Indian society shifted to reinforce the importance of cows in meeting the agricultural needs of society. Harris proposes the belief cows are sacred evolved over time as the importance of cows towards supplying society with food became increasingly important and, subsequently recognized by its members. This occurred whereby the value of the cows was more important for their labour and milk rather than their flesh. Harris argues how farmers who, during periods of draught and famine, slaughter their cows for food would be unable to continue their livlihoods when the rains returned. Thus, over time, the imporance of cows towards meeting the agricultural needs of society became more important than their utility for their meat alone.

Norms that regulate and support support this belief evolved in order to keep cows from being eaten, while simultaneously ensuring their role in providing food for society as a whole. Each new generation has been socialized to these norms and beliefs through religion without ever needing to consider that the cows have ever been anything but 
sacred. Subsequent generations are raised into this system and, through socialization ${ }^{14}$, learn and accept cow worship. In time, socialization of each new generation to the dominant practices of society is what allows the system to reproduce itself. The longer that the belief is established, the greater the semblance that this human-constructed social system is real.

Achieving sustainable change requires a long-term commitment, ideally generational, in order to achieve a corresponding level of support from the underlying beliefs and value emphasis of the social system. Take for example similar public-health related campaigns against smoking or impaired driving. These campaigns have taken generations for the desired activity to become ubiquitous, and further progress remains possible.

To achieve sustainable change, WASH programmes may similarly benefit from ensuring current and subsequent generations are socialized to a value emphasis supporting WASH-related practices through revised norms and beliefs. To truly become ubiquitous among the population, multiple generations must understand and accept the need for the WASH-related activities and practices. Better incorporation of supporting revised norms and beliefs through value emphasis could make it possible to tailor WASH programs to be vastly more effective in the time allotted. In other words, through more direct integration of the underlying social system it may become possible to implement and maintain WASH practices over the long-term. Reports on WASH may or may not

\footnotetext{
${ }^{14}$ Socialization is the process by which people learn to become competent members of society by internalizing the value emphasis, norms and beliefs of society (Marshall, 1998: 624). It is through socialization that individuals learn culturally approved ways of satisfying their biological and psychological needs (cf. Harris, 1979). Socialization is recognized to continue throughout the life-course as the value emphasis of society evolves to satisfy the changing needs of its members.
} 
include such considerations, but should be considered nonetheless, and will be examined further in the next chapter.

Communities targeted by WASH programmes have pre-existing systems that frequently, and often successfully, resist the intended changes. These practices are detrimental to health, education opportunities and economic development, yet remain supported by underlying beliefs and norms (cf. Harris, 1979). Presenting WASH practices to communities is akin to challenging the established reality for these societies.

Berger and Luckmann (1966) argue that humans live in a reality that is taken for granted, and propose the best method for understanding this is by engaging in an understanding of how reality is constructed. In other words, to understand how we come to know reality, it is necessary to understand the reality of everyday life (Berger and Luckmann, 1966). The reality of everyday life presents itself as the reality par excellence, which is taken for granted and organized around the 'here' and 'now' of the present. Foreign examples of reality that enter into the reality of everyday life provide the opportunity to distinguish the difference, and therefore realize how the reality of everyday life is taken for granted. These foreign experiences then become translated back through the reality of everyday life (Berger and Luckmann, 1966).

Presenting the new reality of WASH practices to individuals who were previously unaware, highlights and distinguishes those elements that separate the two realities and contrasts the new reality with the taken for granted nature of the prevailing reality. Individuals then become confronted with a decision of which reality to accept, and which practices to continue. As is the case for most programmes, there is a lack of understanding and belief in the value of the improved practices, other than being 
identified as foreign, more time consuming and, in some cases, more expensive than can be justified.

Thus far, it is assumed that our realities are social phenomena. Now to describe how they come to be socially constructed. The social construction of reality is always accomplished as a collective and is best outlined by Berger (1967), in his model of "world-construction". World-construction refers to how the social system of society is created. World-construction explains how new forms of activity are introduced into a social system and how they are correspondingly maintained, which is critical for any discussion of how WASH-related activities can be sustainably introduced.

Berger (1967:p. 3) prefaces this model by outlining how society is a systemic phenomenon: an entirely human fabrication that acts back on individuals as an objective reality. Through this interpretation he observes how very little in the lives of human beings is directed by instinct and how humans exist within a "cosmos" independent of social structure. In comparison to other species, humans have relatively few instinctual patterned responses hard wired from birth. Unable to rely on these instincts to direct activity, Berger (1967) argues that humans create a normative system or "nomos" to provide patterns for response to various stimuli, and in so doing provide meaning to the cosmos.

Humans rely on intellectual capacity to provide social structure and organization to life. It is within this context that Berger outlines a cycle of externalization, objectivation and internalization that, in sum, allows humans to organize their world and create patterns of experience. This cycle is also useful in understanding how a sustained 
WASH-related nomos can be introduced and through socialization, become internalized by a population.

Berger (1967) explicates how the "nomos" is created vis-à-vis world-construction, which is the process whereby the world is organized and norms develop. This process establishes a socially constructed world, which orders human experiences, creating a nomos. Berger (1967: p.19) argues, "to say that society is a world-building enterprise is to say that it is ordering, or nomizing, activity". He adds that the ordering of experience or nomos is rooted in all forms of social activity and expands as this activity evolves to include ever-broader areas of common meaning. This, in its entirety, is what fills in the aforementioned social system by providing structure to the way humans fulfill the needs of society and its members.

World-construction begins with externalization, which completes the cosmos for humans. Externalization fills the cosmos with social constructions, ways of seeing a worldview. Externalization consists of the physical and the mental manifestation of all individual activities (Berger, 1967:4). The concept implies that humans are externalizing from the beginning of life, without consciousness or intent. The entirety of individual actions and human activity constitute a constant outpouring of externalized activity. Through externalization, patterns of activity form as human nature directs individuals to seek a predictable structure to activity (Berger, 1967:7). Society and culture are both products of the constant and unending externalization of human activity. Adopting patterns of activity provide a sense of predictability for humans, which fill the cosmos with a social structure, thereby compensating for the lack of programmed instincts (Berger, 1967:9). 
In the context of WASH programmes, externalization is accomplished by demonstrating the importance of WASH practices, such as the value of choosing clean water sources over the nearest source, disinfecting and treating water and practicing proper sanitation techniques. The subjective component of externalization in the context of WASH programmes is to provide the education and information necessary for individuals to understand why the aforementioned practices are required. Understanding and awareness of the dangers of the old practices, as well as the benefits of the new practices must be made explicit through externalization of this information.

The second part of the Berger system of nomos creation is "objectivation". This is how humans accept that the social constructions as real, true or honest. To paraphrase Thomas (1923), if humans think a construction is real, they respond as if it is real. Berger (1967) terms the transformation of externalized processes and products into bona fide facts existing outside of the individual as the process of objectivation. Simply put, the socially constructed world becomes theoretically independent of humans when objectivated; actions acquire an existence independent of their producers.

Once objectivated, the socially constructed mental and physical objects of humans come to exist externally from the individual actor and become facts of the collective world. Objectivation renders these as facts, processes and actions independent of humans, setting them free to be capable of acting back upon themselves and to shape future externalization. According to Berger, the collective recognition of objects provides the cohesion required to transmit the nomos, which, in turn, provides an objective reality for all those who share within the nomos (Berger, 1967). In the context of WASH, objectivation of WASH practices would consist of demonstrating benefits of following 
the WASH prescribed practices, as well as the dangers and consequences of continuing the old methods.

Through objectivation, a reality is constructed that is distinct from human subjective reality. The objective reality of society confronts the individual as something entirely external from him or herself (Berger, 1967). The objective reality becomes commonly recognized and imposed on the individual regardless of his or her wishes. This is the coercive nature of society, a capacity to impose objectivated facts upon reluctant individuals (Berger, 1967). These constructions come to exist as "objectively real" phenomena despite being the objects of the collective's externalizations (Berger, 1967).

An example of an objectively real phenomena commonly shared among societies is exemplified by religion. Religion can be considered an objectivated fact that has been both socially constructed and, simultaneously, an entity imposing itself as an external reality. Much like the phenomena of sacred cows in India (cf. Harris, 1979), which itself is a component of a religious belief, once objectified and subsequently recognizable to others, religion coerces society to accept it as a social fact.

Durkheim (1982) described social facts, as "states of the collective mind" that exist independently of humans, yet having a coercive power over the actions of humans. Similar to Berger (1967), on objective reality, the coercive power of social facts manifests to impose a normative order coercing members of society into acting or thinking in certain ways. Similarly, religion has no factual basis and is only supported by its common acceptance within society. Through collective recognition in society, religion exists as a social fact imposing an objective reality back upon society. When religion is 
strong and working, the coercive nature of society takes over and individuals are less likely to question its reality, strengthening the objective facticity ${ }^{15}$.

The facticity of religion serves as an example for potential modeling of WASH programmes. Once WASH-related knowledge and practices have been externalized they need objectivation to become perceived as true and honest; these actions will need to become real to the target population. WASH-related practices will then come to exist independently of their human actors, as objective and subjective facticities capable of acting back on the population to shape future externalization towards WASH practices.

Through objectivation, social facts become transmittable, but still require acceptance to be transmitted effectively. Internalization facilitates the transmission of objectivations whereby objectivated facts become subjectively accepted, through the process of socialization. According to Berger (1967), internalization occurs when the structures of the objective world act on the individuals to form the internal structures of their consciousness. Once internalized, the individual has not only learned these meanings, but accepts and identifies with them. Internalization implies that the objective facticity of the social world becomes a subjective facticity as well; the individual encounters the institutions of the social world as something real and external to himself or herself, thus, becoming real in the consciousness of the individual (Berger, 1967). Through internalization, the socially constructed reality is presented as an objective reality that pervades subjective faculties, thus shaping the worldview of humans.

${ }^{15}$ A facticity refers to the ability for an objectivated social fact to be viewed, subjectively or objectively, by all actors in their social reality in the same manner (cf. Berger, 1967). In other words, a facticity represents a shared understanding of an objectivated social fact by all those who share in the same nomos. 
Internalization of social reality takes place in society through the socialization process. The established institutions of a society become subjectively real as attitudes, motives, desires and goals. Through internalization, the individual appropriates the whole of the societal institutions, along with his or her roles and identity (Berger, 1967: p.17). Internalization also applies to new generations, as it transmits the objectivated meanings, or nomos, via socialization between generations.

The transmission and persistence of the nomos works best when it is taken for granted. Berger (1967) suggests the social world intends, as far as possible, to be taken for granted and is most effective when accepted prima facie. The socialization process is successful to the degree the taken for granted quality is internalized. Berger (1967: p.25) contends it is most desirable for the individual to look upon the key meanings of the social order as inevitable or as "the universal nature of things", suggesting whenever the nomos attains the quality of being "taken for granted, there occurs a merging of its meanings with what are considered to be the fundamental meanings inherent in the universe".

In the case of WASH programmes, a new or revised nomos must be effectively implemented in order to permanently change the WASH-related activities and practices. Without a new nomos to support the changed activities the WASH-related practices will be disingenuous and unlikely to persist if not regarded as real, true or honest. Through the cycle of internalization, objectivation and internalization, a WASH-related nomos can be introduced and, through socialization, become internalized by the community. To what extent WASH programmes attempt to create a new nomos is not clear but should be examined further. 
Assuming the subjective and objective components of a WASH-related nomos are internalized through socialization within the target population, the next step will be to ensure individuals are not inclined to revert to previous normative patterns. As such, there remains the challenge of instilling the WASH practices to the point that they become, as Berger might suggest, taken for granted and perceived as part of the universal order of things.

Berger and Luckmann (1966) argue that the social construction of reality is derived and maintained by social institutions. Alignment of the social institutions is what gives social systems stability and resistance to change (cf. Harris, 1979). Conversely, if the social institutions are aligned to support a new reality, that reality appears more believable and more stable, rendering it plausible.

According to Berger (1967), plausibility structures subjectively reinforce the social order allowing it to be taken for granted by those who share in its reality. When successfully in place, the social order is easier to maintain and produces the requisite taken for granted quality necessary to efficiently sustain the system. Berger (1967) defines plausibility structures as sets of institutional arrangements that support the legitimation of a system by providing those individuals who participate in it the requisite structure to take the reality for granted. For example, most major world religions are supported by various social institutions appearing to believers as self-evident and taken for granted. The resulting reality, upon which the religion is based, is then capable of further shaping and strengthening the social institutions that contributed to its plausibility in the first place.

A working plausibility structure is analogous to a strong foundation that supports 
the creation, maintenance and persistence of what is constructed upon it. It is the base on which a working social system is founded and is reinforced by complimenting components and institutions of the system. The plausibility structure supports the value emphasis and its resulting norms and belief system that, as a whole, provide a sense that the social order is real and of central importance (cf. Durkheim, 1933; Parsons, 1968). It then follows that the new WASH practices must be supported by a plausibility structure that legitimates and maintains their persistence among the population while guarding against erosion from competing beliefs.

Legitimation of the social institutions supports the plausibility structure by justifying the nomos as an objective fact that answers challenges to the institutional arrangements (Berger, 1967). Strong legitimations allow knowledge to be taken for granted and accepted ipso facto. Berger (1967) suggests legitimations are both cognitive and normative and, when successful, propose what is rather than what merely ought to be.

Berger (1967) argues that religion, historically, has been most widespread and effective instrument of legitimation. By aligning the institutional order so that it is interpreted as to hide, as much as possible, its constructed character, Berger (1967) argues religion allows society to forget that this order was "established by men and dependent on the consent of men". Furthermore, religion allows society to believe that by objectively and subjectively following the imposed social structure, it is practiced in order to realize something greater than the individual and to achieve harmony with the fundamental order of the universe. This process allows individuals to locate themselves within a sacred frame of reference and when it comes to religion, the sacred is more 
likely followed than the secular. Thus, Berger (1967) argues, how through religion, the inherently precarious and transitory construction of human activity achieves a semblance of security and permanence, allowing the nomos to achieve a level of ipso facto legitimation.

According to Berger (1967), within a successful plausibility structure, the meanings of its institutions become internalized, and act back upon society to legitimate the nomos as "self-evident" to all actors. To be most effective, plausibility structures must define both the objective and subjective realities of individuals (1967). In other words, an effective plausibility structure legitimates social reality by outlining parameters for individuals' actions externally through the institutions of society, as well as internally, outlining parameters within the individual's own consciousness. The facticity of the social world often suffices for legitimation as long as there is no challenge (1967).

WASH programmes may benefit from legitimation of WASH practices through a plausibility structure that supports the practices objectively and subjectively. If similar concepts are considered in the WASH-related reports and analyses, it may help explain the difficulty which target communities experience in accepting and maintaining the WASH-related practices long-term.

According to Berger, (1967) social reality is naturally precarious and constantly under threat by new externalizations that challenge the established order. Transmitting the nomos from one generation to the next and simple human forgetfulness both constitute challenges to establishing legitimacy, as do direct challenges that arise from "why" questions and conflicting interests. In these instances, the validity of the social order must then be explicated in order to maintain the legitimacy of the nomos. 
Repetition of the objective facticity is important for answering the "why" questions and for instilling reminders against the natural forgetfulness of human nature. Berger (1967) argues that constant reminders disseminated in the form of traditional wisdom, proverbs and moral maxims are effective methods for maintaining legitimation against such challenges. Reminders in these forms effectively explain, transmit and affirm the message "this is how things are done", providing legitimacy to a particular facet of social life (Berger, 1967). These activities align society with a historical perspective providing a sense that the whole transcends the collective, reinforcing the "taken for grantedness" of the system. Investigating how similar efforts are employed in WASH programmes towards maintaining the legitimacy of WASH practices is likely an important consideration for improving the prospect that WASH practices are maintained long-term.

Construction and maintenance of a plausibility structure comprise both a community and individual component. Referring to religious traditions, Berger (1967) considers how religious social orders require specific communities for their continuing plausibility and legitimation. When all members of the social system believe the facticity of the message, the community then becomes an integral component of the structures that reinforce the plausibility structure. For example, the facticity of the sacred cow requires the presence of social structures that encourage the reality to be taken for granted by followers through normative rules supporting and maintaining the beliefs surrounding cow worship.

According to Berger (1967) conversation supports maintenance through shared objectivation with significant others, i.e., friends, family and close peers, by bringing 
about a coherent world-view. Berger (1967) posits that when individuals engage in conversation with significant others who confirm or reinforce common definitions of reality, it supports the facticity of that particular world-view. This is the underlying process whereby the plausibility structure of a particular societal order remains credible. At the macro-level, the plausibility structure of the social order survives only when individuals continue participate in them. At the micro-level, the common acceptance in a belief system is dependent upon continued participation in networks of others who share the same beliefs. Similar processes may support WASH programmes at the macro- and micro-levels by supporting and maintaining the facticity of the WASH practices, and should be looked for in the disparate WASH-related reports and analyses.

The process responsible for this social phenomenon is perhaps best outlined using the "looking glass self" (Cooley, 1909). According to Cooley, every individual becomes a mirror that reflects information back to the actor. Those individuals who are most closely associated with the actor become the primary reference points for self-assessment. When an actor externalizes, he or she is constantly looking at co-presents for cues of affirmation or rejection. The actor then internalizes this information as objective facts used to re-calibrate future externalization accordingly. Throughout this process, the actor is also simultaneously reflecting feedback to actions of others.

Responses or reactions from others are analogous to sanctions conveying approval or disapproval to given activities. Berger (1967) implies the use of sanctions when he refers to the process whereby beliefs are affirmed and subsequently maintained through conversation with significant others. Therefore, when conversing with significant others, it is common for one to receive approval for reaffirming the popular beliefs of the group 
and, in addition, positive reinforcement provided by the group helps affirm the overall credibility of the belief. To paraphrase Goffman (1959), if an individual is to be accepted by a group, he or she must, to some degree, confirm acceptance of the beliefs and value emphasis that the group holds in high esteem.

Conversely, negative reactions from significant others serve to discourage beliefs not shared by the in-group, which similarly discourages the belief from being maintained. This premise also applies to non-active participants within the in-group. For example, in a group of significant others, individuals have an opportunity to directly observe others, proclaim shared beliefs and witness the negative or positive responses to this activity. The individual then decides whether or not to proclaim these beliefs in order to avoid or encourage the same response.

Berger (1967) argues that the entire society must serve to confirm and reconfirm the facticity of the social world for the community at large to serve as a reinforcing mechanism. The importance of this is most apparent when it is absent, as efforts neglecting the importance of the whole group leave fewer members of the population to actively reinforce the social reality. In the context of WASH programmes, targeting certain sub-populations rather than the entire community are more likely to fail because there are fewer individuals within the community to reinforce the WASH practices and activities.

Community support of the nomos allows patterns among values, beliefs and norms to become established and mutually recognizable within the shared social world. The same process is responsible for reinforcing and allowing negative patterns of activity to continue when supported by the value emphasis of the society. For example, various 
practices and activities known to be detrimental to health, such as smoking or binge drinking, persist because they are tolerated and supported by the value emphasis of society.

The community has the capacity to be the greatest steward of its own future. If the value emphasis is successfully revised to make plausible and legitimate the new practices they will be more likely to persist. Conversely, the community may also detract from the new practices if plausibility or legitimacy is not sufficient to revise the value emphasis of the whole.

Given the importance of this process to shaping and reinforcing the value emphasis, beliefs and perceptions espoused by individuals, the approval rewards resulting from espousing beliefs of the group may be an important means by which WASH programs can instill normative sanctions to help maintain and legitimate WASH practices. Once taken for granted, future generations will be socialized to accept the improved WASH practices ipso facto, further reinforcing the "taken for grantedness" of the nomos. Finally, when the institutions of the social order achieve the quality of being taken for granted, their capacity to act back upon society and shape future activity is much stronger, as it appears plausible and is less dependent on the continued support of community members.

In summation, achieving sustainable change in human actions should be considered in terms of how social change happens within a system. Social change happens within a system much the same way that Berger views the nomos filling the social system with meaning. The components of the social system, when aligned to support the nomos, create a plausibility structure enabling the whole system to be taken 
for granted. When the components of the social system are taken for granted, individual action is aligned in a manner that supports the maintenance of the system. When the social system is not taken for granted, it is then necessary to provide legitimacy to the components of the system in order to ensure maintenance of the system as a whole.

It is important to see how a system gains stability when its members share the same values. Emphasis emerges to prioritize the values most significant for fulfilling the needs of the society as a whole. Norms and beliefs emerge from the value emphasis to reinforce and influence individual action in a way that best meets the biological and psychological needs of the collective.

In the context of WASH, programme designers may benefit from considering target communities as individual social systems. These systems exist in a precarious stability that, by virtue of "systemness", will act to resist change in order to preserve the strength of the system. The decisions made individuals regarding their actions are a reflection of the prevailing value emphasis, which subsequently influences their norms and beliefs. Therefore, any analysis of WASH programmes should take into account how human activity is directed by the underlying social system.

The way humans create their social system is called world construction. World construction refers to how humans create their social reality as an entirely human construct, yet perceived by humans as an independent entity capable of acting back upon them. Through the cycle of externalization, objectivation and internalization humans create a nomos to structure and provide patterns for social life. The nomos provides structure and organization to the social life of humans who otherwise lack the requisite hard-wired dispositions to do so instinctively. Whenever the nomos attains the state of 
being taken for granted, there occurs a merging of its meanings with what are considered by humans to be the nature of things, which is often perceived as the way things have always been.

A successful plausibility structure is integral to achieving the "taken for grantedness" of the system because it provides the requisite social elements for the system to be internalized ipso facto, through socialization. In other words, an effective plausibility structure helps the social system to be taken for granted, enhancing the capacity of the system to act back upon society and, simultaneously, strengthen the legitimacy of the system.

In the context of the current literature on WASH, it is apparent that programmes are competing against an already established plausibility structure that supports the previous norms and beliefs. If the revised social system does not achieve stability, competition with the practices of the existing system will be too great, explaining why communities frequently revert to the previous system, demonstrated by the high rate of programme failure.

On the other hand, the likelihood that WASH programmes successfully and sustainably change how individuals practice sanitation, hygiene and access to water may be much greater if WASH practices can be supported by a revised plausibility structure. To do this, programmes may benefit from considering how to better legitimate and subsequently maintain the improved WASH practices so that they may be taken for granted and eventually become perceived as the way things have always been. This may be possible by demonstrating the tangible benefits brought on by the WASH practices, so that it may be possible for the value emphasis to, in time, become revised to place greater 
priority on accepting and practicing the WASH practices. In so doing, respective changes to the shared norms and beliefs of the social system would likely follow and become objectivated into the new plausibility structure and internalized, through socialization by subsequent generations; effectively securing the "taken for grantedness" of the practices and generating considerable momentum for the maintenance of the practices for the longterm. This would complete the nomos for WASH and only leave the challenge of implementing this theoretical supposition within the framework of how current WASH programmes are delivered, which will be examined in the next chapter. 


\section{Chapter: Application of Theory}

Chapter one demonstrated how water scarcity is a serious and far-reaching problem causing millions of unnecessary deaths each year. Sufficient quantity and quality of water is the key to reducing these unnecessary deaths and achieving progress on all of the Millennium Development Goals (MDGs). Achieving these goals would translate into far reaching economic benefits, opportunities for healthier more productive lives and even tremendous potential for GDP growth for those countries crippled by populations without improved water and sanitation (Hutton and Bartram, 2008). To achieve these attainable gains, greater emphasis and a sharper focus will need to be placed on water and sanitation, specifically WASH programmes, and how to better enable them to ensure populations continue to collect water from improved sources and to practice improved sanitation upon programme completion.

In chapter two it was demonstrated that as many as half of all WASH programmes fail, often unnecessarily. Programme failure results in populations never achieving the opportunity to benefit from improved sanitation, children deprived of education because they are collecting water or are too sick or malnourished to attend school, as well as new generations being raised without improved sanitation ultimately perpetuating the same unnecessary poverty and sickness the WASH programmes intended to eradicate in the first place.

Currently, there are no compelling explanations offered in the available postmortem reports and evaluations of WASH programmes that adequately explain the high rate of failure. Instead, these documents offer disparate accounts of specific programmes without adequately contextualizing why the programmes either failed or flourished. 
Greater success may come from a better understanding and contextualization of the data in the literature. This chapter will bring together a number of questions raised in the context of the theory offered in chapter three with the hope of providing some insight on why so many WASH programmes fail.

Analysis to determine if WASH programmes are incorporating the theoretical considerations described in the last chapter will require examination of the data presented in chapter two. Many questions can be asked of the examples of failed programmes presented in chapter two. The first of these would be to determine if WASH programmes are effectively considering the social construction of reality (cf. Berger and Luckmann 1966), and what efforts, if any, are in place to encourage WASH practices to become part of the social system?

The social construction of reality, or "world-building", is a process whereby a social system or nomos is created (cf. Berger, 1967). The nomos structures social life by providing set patterns of activity and by organizing human experience. This process consists of a constant cycle of externalization, objectivation and internalization, which establishes the socially constructed world and is how new patterns of activity are transmitted.

All human activity is socially constructed; what was initially nothing becomes real when externalized. Once it is externalized and recognizable to others, it is objectivated, becoming a transmittable fact of social life. Finally, through socialization, individuals internalize the objectivated and transmittable facts. This process occurs constantly through every human action, and from it, patterns of activity form creating a nomos, or reality, which constitutes social life. 
In the context of WASH, programme implementation it is essentially the task of encouraging the adoption of a revised nomos for the improved WASH-related practices. These practices constitute a new reality for a local population that confronts the prevailing reality as foreign and different. In order to sustainably change the WASHrelated practices for the long-term, WASH programmes must ensure that the new reality, in its entirety, is internalized and accepted. Acceptance of the new WASH reality equates to whether or not programmes will have a chance of being successful.

Roughly 30 to 50 percent of all WASH programmes eventually fail and developing countries are, quite literally, littered with broken water pumps and sanitation facilities (cf. Blue Planet Run Foundation, 2012; International Institute for Environment and Development, 2009; International Water and Sanitation Centre, 2009; Water for People, 2013). The literature, when available, suggests that programmes generally fail when the community reverts to old habits because they choose to, or when they have no choice but to revert to the old habits when facilities break down. When this happens, the new nomos to support the continuation of the practices or the maintenance of the facilities is not successfully objectivated and internalized. Given the importance of individuals accepting the new reality, the data should be analyzed to determine how WASH programmes become part of the social system.

For the majority of WASH programmes, implementation consists of prescribing a new reality for intimate routinized activities within a community. Members of these communities are then confronted with a decision: which reality should they accept? When WASH programmes successfully encourage long-term activity change, it is because the community is choosing the new reality. Conversely, when the programme 
fails, the community is choosing the familiar and known reality over the unknown. In many cases, the new reality offered is not compatible with the familiar way of life among the community.

Most WASH messaging consists of explaining the unsanitary actions through the social and cultural lens of the experts overseeing the programme rather than from the perspective of the population undergoing the change. In many cases this constitutes an entirely new reality that conflicts with the worldviews, or nomos, of the target population. For example, the failed programme in Ché, Guatemala (cf. Breslin, 2010) never became a part of the way of life of the community for a number of reasons. The most obvious impediment to adoption was the fact that half of the community was inadvertently excluded from the benefits of the programme. By only completing latrines for half of the community, the original implementing group, at the very best, only made it possible to change the reality for half of the community. When any part of the community is excluded from participating in the programme it does not allow for the entire group to share in the same social reality, which would be necessary if there is to be any chance of the improved practices being adopted. Given the importance of sharing in the same social reality, any serious implementation would require an equal footing from which all members of the community could begin to learn and adapt to the new reality being offered, which the original implementers clearly did not factor into the programme.

On the other hand, the implementers may have incorporated a component that respected the socially constructed nature of society through educational campaigns that built awareness when the latrines were being constructed. Unfortunately, the literature does not record the level of sanitation education or education provided to the community; 
therefore, it is not possible to discuss how this approach may or may not have complimented the use of the latrines.

It is possible to surmise that the result of having the latrines funded for and constructed by the implementing organization constituted the entire programme operating outside of the social reality of the community. As Breslin (2010) notes, even if the organization had completed latrines for all of the families, the same problem would have occurred when a new family needed a latrine. Providing these facilities for villagers is not realistic and could not happen without external support for the community. Simply put, the artificial construction was not plausible; the villagers saw little initial value, which resulted in villagers not perceiving any responsibility or impetus to continue their construction. Without this, there could be no formation of patterns because the community did not build additional latrines. Without this process, they could not perpetuate a new nomos.

Other programmes, such as the example described by Saboori et al. (2011) and Kennedy and Nilsson (2012) appear to have taken into account the social construction of reality. Both of these programmes, WASH in Schools and Community Led Total Sanitation (CLTS), to some extent, indirectly incorporated the social construction of reality.

In the example of WASH in Schools in Nyanza, Kenya (cf. Saboori et al., 2011), an indirect application of the social construction of reality theory is evident in how WASH in Schools made choices that were built around the social reality of the existing school system. Specifically, the programme messaging passed through existing channels of education in a manner compatible with how children are educated and socialized. In 
addition, the programme is designed to harness the potential of the children distributing the WASH messaging to their parents, communities and hopefully their own children in the future.

This approach has limitations which ignore some inconsistencies between the intended approach and the social reality of these communities. Specifically, targeting the children as "change agents" is inconsistent with the low status ascribed to children in most developing cultures. A more appropriate approach, consistent with the social reality, would be to target women in these communities, who are the individuals most responsible for managing the domestic water supply, cooking and ensuring the availability of soap (cf. Gleick et al., 2011; cf. Tandon, 2007).

Selecting the appropriate community members most consistent with the social reality is certainly an important consideration. Some development programmes have found success by explaining the unhealthy activity in methods more recognizable and consistent with the beliefs or reality of the target population. For example, Technische and Zusammenarbeit (2007) describe a similar process used by the FANKANTA project aimed at sustainably reversing the deep-rooted and common tradition of female genital mutilation in Senegal. Much of the success of this programme was attributed to the role of village elders who were targeted to deliver the message in a familiar and consistent context. Although the elders had traditionally been responsible for continuing to uphold the tradition, their acceptance of the new practices legitimated the message and provided a sense that the new social practice was legitimate.

Engineers Without Borders used a similar approach in the implementation of a CLTS programme in Malawi (Kennedy and Nilsson, 2012). As described in chapter two, 
the programme began with a survey to determine the approach for implementation. At the same time, village leaders and local government officials were engaged and brought on board with defined roles to help establish the programme. This approach respected the social construction of reality by tailoring the programme to the reality of the community, and similarly to the FANKANTA programme previously mentioned, attained buy-in and participation from community leaders from the outset. In contrast to WASH in Schools, the CLTS approach recognizes the importance of targeting the entire community while also targeting the leaders as the principal "change-agents" and requires the participation of the entire community to meet the programme targets.

In all instances, consideration of the social reality is important. As demonstrated in the sanitation programme in Ché, Guatemala, without any efforts to change the social reality of the community, there was no chance of programme success. Without efforts to change the social reality, programmes cannot be sustained when the implementing organization leaves the community. Conversely, the other two examples demonstrate that it is possible for programmes that address the need for social change to have a chance for the messaging to be objectivated and internalized.

Consideration of the social construction of reality is an important step, but it alone does not constitute enough to ensure programme success. What happens within the community and how the socially constructed reality is maintained is an important element to understanding why so many WASH programmes result in communities reverting to collecting water from unimproved sources or reverting to unimproved sanitation practices such as open defecation. As discussed in the last chapter, the constructed social reality is akin to a system that seeks stability by aligning the needs of society with the needs of its 
members. This alignment is what gives social systems stability and, at the same time, predisposes the system to resist change because societies have an urge to survive, which is accomplished by aligning the needs of individuals with the needs of the social system (cf. Harris, 1979). The result is the emergence of culturally approved methods for satisfying these needs through patterns of activity that guide the choices individuals make in their daily lives. Not addressing this underlying system is likely to result in individuals reverting to the pressures of the existing system.

In the context of WASH, the precariousness of the improved practices stem from resistance from other components of the system acting to reverse the changes. When the improved WASH-related practices are introduced to the community, other aspects of the system discourage the improved activity because the new practices are not congruent with other elements of the social system. Given the importance of ensuring the long-term adoption of these practices, the body of WASH literature should be considered in terms of how programmes support the new reality by addressing other components of the system.

Looking, once again, at the original implementation of the programme in Ché, Guatemala, it is apparent that the importance of the underlying social system was overlooked. By virtue of neglecting any social component and only providing half of the community with latrines, there was nothing to prevent the system from reverting to the previous reality. In other words, without any social component to support the use of the latrines, it became too easy for villagers to revert to their previous ways of life. Furthermore, as was exemplified by the community, given the option to build the remaining latrines or do without, the path of least resistance was clearly to go without. 
Because half of the community continued to practice the unimproved activities, there existed relatively no social pressure to prevent reversion to the unimproved activities when, for example, the latrines stop working, become full or require repairs.

The WASH literature often calls for the creation of an enabling environment to support the changes to the social system that are likely to revert without support. The community-based approach, which was outlined in chapter two, can be considered a form of programming which is in line with the concept of treating society like a system. This approach is based on creating an enabling environment for WASH practices by addressing the entire community so that all members are included in the programme and by aligning various external elements to support the continuation of the programme (Tamas and Mosler, 2011; Pokharel, 2012; Peal et al., 2010). This resembles treating the community like a system because it addresses the entire community and reduces external components of the system with the capacity to resist change. In a study of interventions for the sustainability of water treatment-related practices, Tamas and Mosler (2011) conclude that interventions should aim at habit formation and providing social support as it is more effective than attempting to directly convince people of the benefits of the new method.

WASH in Schools and CLTS are both types of programmes consistent with an enabling environment-based approach. The WASH in Schools pilot programme in Kenya was specifically created to ensure that WASH practices would be continued after the implementation period. The intention of the programme was to ensure that all necessary elements were in place prior to handing programme authority to the local community. These measures included ensuring that the community had the necessary knowledge and 
ability to finance repairs should any of the facilities become non-functional; that the community had working water sources; that the teachers were all trained to treat the water with chlorine; that there was supply of chlorine and soap available; as well as where to get additional chlorine and soap as needed. In addition, parents were sent messages intended to persuade and inform the larger community of the benefits of the WASH practices (Saboori, et al., 2011). All of this was intended to ensure that students, teachers and the community would actively continue the improved practices when confronted with the choice to either continue or revert.

Despite these efforts, Saboori et al. (2011) found that none of the 55 participating schools had sustained all of the improved activities. Somehow and despite the enabling environment in place, something went awry and the vast majority of the schools reverted to the unimproved activities. Specifically, when the schools ran out of chlorine and soap, repairs were needed or when new teachers joined the faculty, few schools actively chose to continue the WASH-activities.

Saboori et al. (2011; p. 310) attributed project failure to weaknesses in one or more of the components of the enabling environment, implying that future sustainability requires greater cooperation on multiple levels within the community, including various levels of government. This certainly appears to be an appeal towards ensuring resistive elements of the system are aligned to support programme success. This model is inconsistent with the findings of the programme evaluation. There is no guarantee that greater government or any other external support will ensure that the WASH practices are continued. 
Financial stress was the most prevalent reason why schools did not continue the WASH activities. In most instances, the costs were deemed more than could be afforded by the school and community to warrant continuing the practices. It is possible that greater government funding may have helped to alleviate these challenges. On the other hand, reasons why new teachers were not trained to continue the WASH programme cannot simply be justified by a lack of government support or funding since the cost for these activities would have been relatively minimal and could have been included in the basic orientation for new teachers.

The CLTS programme in Malawi provides further evidence for why additional government support is unlikely to dramatically improve programme outcomes. The programme had active support from the local government, and yet it failed. More so than the WASH in Schools pilot programmes in Kenya, the CLTS programme in Malawi used an enabling environment approach to encourage participation among the entire community, which was supported by programme officials regularly collecting data to track the level of participation. Yet, just like WASH in Schools in Kenya, the CLTS programme in Malawi failed once it was handed over to the local community and government for continuation.

Kennedy and Nilsson (2012), members of the Engineers Without Borders team that implemented the Malawi programme, attribute programme failure to the fact that the implementing NGO built the programme around its own budget, which was unsustainable for the local government to continue. The costs associated with paying enough workers to monitor the community and the cost of the system to collect and gather data on participation levels proved to be more than the government could afford. When the 
implementation phase was completed, earning the village the status of "open defecation free", the programme was immediately considered a success and was handed over to the local authorities despite an understanding that the government could not afford to continue with the same level of support.

However, it is important to note that the government only took over once the community had passed the CLTS programme and had been declared "open defecation free". The goal of the government was to continue oversight of data tracking of the improved practices within the community. Unless the data tracking was the primary motivation for why the community was continuing the improved practices, which is unlikely, then the government cannot be assessed as having all of the responsibility for the failure of the programme.

Stopping the data tracking, once the community had successfully achieved "open defecation free" status, should not have prevented the villagers from continuing to practice the improved activities. This suggests that the villagers should have been capable of continuing the practices even though the government oversight failed.

To some extent, both programmes considered the communities to be systems because they focused on changing and aligning other parts of the system to support the revised practices. In both instances, however the enabling environment that was established was primarily objective and focused on material structures, money and relationships rather than the importance of the subjective choices that individuals must make to actively continue the WASH practices. Both programmes should have supported the system by providing the underlying elements necessary to sustain the improved practices. 
The enabling environment approach lacks a component that supplants the previous normative activity with the adoption of values, norms and beliefs supporting the sustained WASH-related actions. Since actions of individuals are largely determined by the system in which they live, only changing certain components of the system, and not addressing the overarching structure, will consistently result in reversion to the practices of the previous system. Only targeting external elements of programmes omits many other factors such as value emphasis and beliefs and norms, which influence and reinforce human activity. As such, the overarching social system must be addressed as the source of what is driving the underlying value emphasis and, ultimately, the actions of individuals.

Value emphasis is always systemic and is directly related to the values shared by the members of a society. Durkheim (1909) suggested value consensus is what allows society to operate properly. Similarly, Parsons (1968) argued that norms and beliefs become part of motivation through shared value emphasis among members of society. In this regard, norms and beliefs are an extension of the value emphasis of society that evolves to satisfy the needs of the system (cf. Harris, 1979). Given that value emphasis is responsible for generating the necessary beliefs and norms to satisfy the needs of the system, the literature should be analyzed to determine how WASH programmes are addressing the importance of value emphasis.

Consideration of value emphasis appears to be present in some studies, although not identified explicitly. An example of this can be drawn from a study of water and sanitation-related activities in Kenya (Levison, 2010). This study found individuals frequently chose to collect water from the polluted water of nearby Lake Victoria despite 
the availability of a clean source in a nearby forest. Rather than collecting water from the clean source in the forest, members of the community explained that it was more desirable to collect water from the contaminated water of the lake, which is in the opposite direction of the forest source. Interviews were conducted with villagers in an attempt to explain why they continued to use the polluted water from Lake Victoria. It was found that villagers perceived acquiring water from Lake Victoria more desirable because it is seen as an important resource for the community, adjacent to the main income source and because it acts as a meeting place for community members. Without making it explicit, these explanations reflect a conflict at the level of the value emphasis of the group that is not congruent with the values required for improved WASH practices to become adopted.

When these individuals chose the contaminated lake source, they likely did so because the value emphasis of the social system placed less value on clean water than the value given to the ability for individuals to socialize or earn income. The latent function of these activities is that community members are re-affirming commitment to the larger group (cf. Merton, 1968). These activities are more important to village members because they have more tangible consequences which, through value emphasis, become internalized into the norms and beliefs of the population. Encouraging sustainable changes in WASH-related activities will need to ensure that a greater value emphasis is placed on clean water, sanitation and hygiene over other tangible consequences, which generally tend to be financial in nature.

Communities often demonstrate that they consider water and sanitation issues to be of low value, and are reluctant to spend their own resources to maintain the provided 
facilities as was the case in Ché, Guatemala (cf. Breslin, 2010). When the original implementing group ran out of funds, they had only built latrines for half of the community. Since there appears not to have been any consideration given to the importance of supporting the activities through the social system, the values of the community never shifted to place greater emphasis on using the latrines. Given that the social reality was the same before and after the organization left the village, the remaining facilities were never built and the community still awaits the free construction of the remaining latrines.

When the organization Water for People offered the community of Ché an opportunity to help build the remaining latrines, the village members refused because they perceived sanitation as something that is provided for free (Breslin, 2010). The organization argued that funding was critical to the success of the project, as all water systems and sanitation facilities require maintenance at some point. Having the community provide funds at the outset is critical to keeping the facilities operational when they need repairs or fail (Breslin, 2010). For this method to be successful, programmes must ensure that water and sanitation are sufficiently valued by the communities and that they are willing to divert what limited resources are available to keep the facilities operational and ensure that the programmes are sustainable when handed over to the local community. This is not possible without demonstrating the importance of clean water and sanitation over the previous activities which have more tangible benefits.

Breslin (2010) argues that as long as communities are provided facilities without incurring any up-front or recurring costs, community members will have no 
understanding of what it will cost to replace or repair the systems and, as a result, may be less likely to value it. These types of programmes have conditioned communities to believe that they do not have to pay for improved water and sanitation. Although it is likely that the community can afford to pay for repairs if it chose to, this method of programme delivery creates an unhealthy dependency. Programmes that encourage dependency fail to address the shift in value emphasis needed to sustain improved practices and may discourage communities from taking responsibility for their sanitation.

Breslin (2010) notes how Africa, Asia and Latin America are littered with failed WASH projects that were provided for free, where communities and local governments were never asked to finance any part of the investment. There is a common perception throughout the WASH sector that rural communities are "too poor", "too disorganized" or "too uneducated" to actually lead and pay for their own development (Breslin, 2010; Ulrich, 2012).

These perceptions are largely inaccurate. The WHO (2012) admits that the capacity of combined household and private investment in water and sanitation programmes could represent a significant source of financing and could provide considerable support to the operation and maintenance of facilities. The first chapter discussed the disproportionately high costs that the poor incur for water from third party merchants. In addition, supplementary costs for healthcare and medicine incurred as a result of inadequate sanitation and contaminated water further reveal that communities do have some funds available but choose to direct it elsewhere. Furthermore, lost income as a result of time spent collecting water or from being sick and unable to work limits additional income to pay for water and water-related services. Unfortunately, it often 
comes down to a matter of choices as communities do have the ability to fund repairs and maintenance, they just choose not to. It appears that the decision of whether or not to provide upfront costs are largely dependent on the perceived value that individuals and their communities place on clean water rather than dealing with the consequences of lack of water.

A lack of value attributed to improved practices is also evident in some of the communities described by Saboori et al. (2011). Schools were eventually faced with decisions of whether to continue the improved practices amid insufficient funding which resulted in community members being asked to help cover the additional costs. Although the WASH in Schools programme attempts to change the value emphasis for WASH within the confines of the school system, the larger social reality of the community is left unchanged. Continuation of the improved practices may be possible in the school if entirely contained, but once challenges to the system arise, such as the need to purchase new supplies, pay for repairs or train new teachers, these decisions become based on the social life of the community.

There is evidence that the WASH in Schools was unsuccessful at improving value emphasis for WASH. Primarily, the programme only supported improved practices within the context of the school; parental participation was not directly targeted, and given the low social status of students within the larger society it is unlikely the WASH messaging was received in their households. The result was that the value emphasis of the social reality of the community prevailed over the intended new value emphasis that was sought within the school. Challenges to the new WASH reality are met with reversion to the previous reality. This is perhaps most evident when looking at the two 
schools that were considered to have been most successful. Both of these schools sufficiently prioritized the funding of repairs to maintain the facilities, continued to provide soap and water treatment products, and both also trained new teachers. This suggests that for these communities, WASH principles were valued at a greater level than the others.

Such programme failures pose a considerable challenge for sustainability, as it is unlikely that communities will sufficiently prioritize the construction or maintenance of water and sanitation facilities in a way that will adequately retain or reserve funds to maintain these facilities once the programme implementers have left the community. Consequently, generating funds for ongoing programme operation and maintenance is a persistent challenge and has been identified in numerous reports.

For example, in the CLTS programme in Malawi a lack of government funding for the continuation of programme oversight was considered to be the reason why the programme failed. On the other hand, if the implementation phase was successful, the improved practices should have continued despite the stop in data collection as the programme had already been declared a success and the villagers should have been able to continue the practices without oversight. Even if the local government had continued supporting the practices and collecting the CLTS data, there is no guarantee that the community would have actively chosen to continue the CLTS activities.

An alternative scenario, explaining why the activities were not continued, suggests that when the data collection stopped, so did the improved activities. This demonstrates that the motivation for practicing the improved sanitation was not tied to a collective belief in the value of the health benefits, but was instead tied to a need to 
satisfy the data collection in order to earn rewards. This indicates that what appeared to be a successful implementation leading to the declaration of the community being an "open defecation free zone" was actually based on the community seeking the rewards along the way. The implementation process was not actually changing the value emphasis of the community to better support WASH-it was simply linking the practices with tangible rewards.

This relationship is most apparent when the village headman, who upon discovering the better rewards offered by a different NGO in a nearby community, began bartering with Engineers Without Borders for comparable rewards in his community. Ultimately, when the village headman learned he would not receive the same tangible benefits as the neighbouring community, he told the villagers to stop participating in the CLTS programme. Any increase in value emphasis for the CLTS practices never became real to the community, as the participation of the community was linked to rewards. When the rewards were deemed to be unsubstantial, one of the more external components of the system chosen to help align the messaging denounced the program, likely waiting for a better funded NGO to set up camp and try the CLTS programme again with better rewards.

All three of these examples present situations where the value emphasis of the communities was not revised to place sufficient importance on sanitation compared to those elements more tangible and proven to satisfy the biological and psychological needs of communities (cf. Harris, 1979). What appear to be lacking are the tangible benefits of WASH practices that, over time, will improve the health and quality of life for 
those practicing them, and subsequently legitimate a revised value emphasis supporting the WASH practices.

A value emphasis that does not support WASH practices ensures that the community reverts to the previous activities. To avoid this, the tangible benefits of the new WASH reality must be legitimized and made to be plausible. Berger and Luckmann (1966) argue that the social construction of reality is derived and maintained by social institutions. Alignment of the social institutions is what gives systems stability and resistance to change (cf. Harris, 1979). Conversely, if social institutions are aligned to support a new reality, that reality appears more believable and more stable rendering it plausible.

According to Berger (1967), plausibility structures subjectively reinforce the social order, and through the alignment of institutional arrangements, support the legitimation of the system by allowing it to be taken for granted by those who share in its reality. A plausibility structure for WASH requires that social institutions are legitimated in order to maintain their credibility so that the new system achieves a semblance of reality and appears important to social life.

To be most effective, legitimations must define both the objective and subjective realities of individuals (cf. Berger, 1967: p. 32). According to Berger (1967), the facticity of the reality must become internalized and act back upon society to legitimate the nomos as "self-evident" to all actors. The firmer the facticity of the plausibility structure, the firmer the reality will be "based" upon it. Accordingly, the less firm the plausibility structure, the greater the need for legitimations. A working plausibility structure creates legitimacy of the social reality, making the reality seem real and 
important. Legitimation allows the system to be accepted ipso facto, with new generations raised to share in the reality and accept it as the only way.

In the context of the WASH programmes exemplified above, a need for legitimation is particularly evident as the programmes are competing against an established reality, supported by the value emphasis of each community with its own norms and beliefs encouraging the unhealthy activities. In light of this, the recurring examples should be analysed to determine if the programmes are legitimating the WASH practices in order to support revised plausibility structures for the improved activities.

It is quite apparent that there was no consideration given for the need for a plausibility structure or legitimacy to support adoption of the improved practices in either of the attempts to improve the sanitation conditions in Ché, Guatemala. In the first instance, the original implementing organization created a false reality for the village that was not plausible for the community to continue on its own. In addition, there is no evidence that the organization attempted to legitimate the use of the latrines through other approaches to support the construction component of the initiative. In the later attempt by Water for People to complete the latrines, it is not clear whether the organization made any attempts to legitimate its approach by demonstrating the tangible benefits of sanitation to the community.

Programmes attempting to create an enabling environment to support the improved practices appear similar to establishing a plausibility structure to support WASH, although their effectiveness and implementation tend to vary. As previously discussed, the literature depicts a need for an enabling environment to be established in the implementation process of WASH programmes. The purpose of the enabling 
environment is to ensure that the improved practices are supported by external elements that reinforce the continuation of WASH practices, but this notion lacks the importance of the subjective requirement necessary to also support the continued practices. A plausibility structure for WASH must ensure that choosing the new reality over the old is an obvious and easy choice. This can only be accomplished by legitimating the new reality both objectively and subjectively.

For example, the enabling environment approach of the WASH in Schools pilots in Kenya (Saboori et al., 2011) was designed to ensure continuation of the new reality by ensuring that all of the objective components could resist the change. Unlike the programme in Guatemala (cf. Breslin, 2010), the WASH in Schools pilots provided the necessary training to teachers and students and established funds and supplies to be used by the schools and communities. These efforts should have been sufficient for the programmes to be continued beyond the implementation stage. Saboori et al. (2011) found that schools that did not purchase additional treatment products responded that they chose not to because they did not consider water treatment a sufficiently high priority to justify the increased expenses and similarly so for the schools that did not repair the water storage containers and those schools that did not replace the chlorine tabs or soap. Subjectively, the programmes were unable to legitimate and demonstrate the tangible benefits of WASH to the larger community resulting in no change to the value emphasis and, unsurprisingly, the programmes eventually failed.

Although none of the 55 schools were considered a success against the preestablished criteria for success, two of the schools were considered relatively successful by having met a number of the criteria, of which some important similarities were 
present. Judging against the criteria for success, Saboori et al. (2011) found that both schools reported always treating the drinking water and, more importantly, actively repurchasing water treatment products as needed. Both schools also had high levels institutional support by ensuring that new teachers were trained in WASH practices and were actively carrying out WASH-related activities, such as latrine construction outside of school hours. Furthermore, both schools demonstrated budgeting for WASH resources and activities through school funds as well as parental contributions. Lastly, data collection activities were practiced in both schools in order to monitor the health benefits and the decrease in absenteeism following the implementation of the WASH programmes.

Through these additional activities, the value emphasis supporting the WASH practices was revised to sufficiently prioritize water treatment and hygiene practices. Particularly, the collection of data played an important role in legitimating the improved practices. Specifically, tracking the health benefits experienced by the students demonstrated the value of the improved practices, which likely provided reinforcement to the schools in order to continue the WASH activities. Saboori et al. (2011) contend that the positive results were one of the principal drivers of why these two schools continued to endorse the WASH-related activities in the community and why the community was willing to fund the additional expenses at the schools.

Similarly, the CLTS programme in Malawi was intended to create an enabling environment to support and legitimate the WASH practices (cf. Kennedy and Nilsson, 2012; Peal et al., 2011). Objectively, the programme created an artificial environment that could not be sustained by the local government. Subjectively, the programme failed 
to demonstrate tangible benefits in the intended health outcomes because the communities were preoccupied with short-term rewards that the program was providing as the community met its CLTS goals.

All three programs failed to institute a plausibility structure to support the practices because they did not legitimate tangible benefits to the target populations. Programmes that set out to create an enabling environment appear to have had similar intentions of creating a plausibility structure, but only targeted objective external factors. Subsequently, the enabling environment approach did not amount to the same thing as a working plausibility structure because it lacked the subjective components to ensure a strong foundation supporting the creation, maintenance and persistence of what was constructed upon it. Without legitimation of the practices to change the value emphasis, the programmes were unable to establish a plausibility structure to support the new reality.

If a plausibility structure can be successfully put in place or, at least, be revised to support the WASH practices, maintenance is still necessary to counter challenges as they arise. According to Berger (1967), legitimation of the plausibility structure requires constant maintenance in the face of challenges to the social reality and the natural forgetfulness of human nature. Mechanisms to maintain WASH practices are necessary to prevent reversion to the previous activities when presented with challenges, such as facilities breaking or depleted supplies, or any situation that arises where it would be easier to revert to the previous system. Maintenance of the system takes time and programmes need to support the new reality over an extended period of time after implementation. If the maintenance allows challenges to be successfully thwarted, each 
new generation will be raised entirely within the new social reality where the improved WASH practices are the norm.

Ensuring that communities actively choose to continue the WASH practices will not happen until the activities are taken for granted and become the natural choice when confronted with a challenge. WASH programmes must leave communities with the subjective and objective capacity to cope with these challenges, and more importantly, to choose the improved actions each time. To what extent the WASH literature depicts the consideration of maintaining the WASH practices may provide insight into why so many programmes eventually fail.

Berger (1967) argues that systems must be designed to combat the "forgetfulness" of human nature by building in ritualistic instruments. Maintenance of WASH practices could be most effective when there is broad participation from the entire community, reinforcing the legitimacy of the new reality (cf. Cooley, 1909).

Maintenance of the plausibility structure requires that programmes create the necessary conditions for villagers to choose to continue WASH activities when the implementing organization has left and the community is responsible for continuing the new practices. The example in Ché, Guatemala (Breslin, 2010) is an illustration of a worst-case scenario where there is no evidence of the consideration of the time that is necessary for the programme to successfully encourage a change in the sanitation activity of the community. By virtue of expending its resources prematurely, the implementing organization was unable to change the value emphasis for WASH, in turn, the practices were not legitimated and support to maintain the facilities and practices was non-existent. Additionally, the community declined to construct the remaining latrines even when 
presented with the opportunity to have them largely subsidized. It can be reasonably assumed that the community would have ignored any repairs needed to the latrines because the programme had no component to maintain the new reality.

Looking at the other examples where implementation phases were completed, suggests the new WASH reality is not being maintained. Both of these other programmes were structured around targeting changes in the WASH-related activities of village members with a focus on creating an enabling environment to support maintenance of the practices. Both programmes were celebrated as successes upon the completion of the implementation phase, yet failed when handed over to local authorities to maintain. However the fault should not be placed on the maintenance phase, as it was the implementation component that failed to instil value or legitimate the facticity of WASH. Without achieving legitimacy during implementation, there is nothing to maintain once the programme is handed over to the community.

In conclusion to the evaluation of the pilot programmes, Saboori et al. (2011) argue that a number of external enablers must be satisfied in order for WASH programmes to successfully maintain the WASH-related actions beyond the implementation process. Specifically, Saboori et al., consider that, "true project sustainability involves a complex system of inputs and relationships across multiple levels, extending from decisions made at an individual level upwards toward policy created at the government level" $(2011 ;$ p.310). These recommendations call for greater government support to provide reliable funding to the programmes, greater integration of the WASH practices into regular school monitoring, systems of accountability within the schools linked to performance measurement of the head teacher and creating a "school- 
based monitoring system" at the schools, community and district levels to track progress and the health of students. These recommendations may, over time, turn out to be helpful at maintaining the practices by ensuring accountability among the teachers and regularity in government funding, however, the more serious challenge of addressing the underlying social components remain. The implementation process must leave the community with legitimated practices that need to be maintained. Without changing the value emphasis to support the improved practices during implementation, there is no point trying to maintain the improved practices, as they never existed in the first place.

The same can be said for the approach taken by the CLTS programme in Malawi (Kennedy and Nilsson, 2012), which artificially legitimated the CLTS practices by linking them to rewards. The community actively participated in the CLTS activities as long as they were tied to rewards. When the community headman did not find the rewards sufficient he told the community to stop participating in the programme. The community connected programme legitimacy with tangible benefits afforded by the rewards. This means that when the programme was handed over to the local government, regardless of its funding situation, there was nothing for it to maintain. The implementation was responsible for the failure of the programme, yet it was not until the local government assumed ownership of the programme that it became apparent the community was not going to continue the CLTS activities.

In all three scenarios, programmes were considered a success early on, once all of the deliverables had been provided and goals checked off. According to Breslin (2010), this approach secures funding, looks good and makes donors happy. The implementing organization moves on when implementation is completed, but without first successfully 
establishing a plausibility structure for the improved activities, resulting in nothing for the communities to maintain.

Assuming the other programmes are more successful at the implementation phase and are able to legitimate the improved activities, maintenance requires patience and time for the practices to become legitimated and accepted ipso facto, which, surprisingly, is not incorporated in any of the example programmes. This is another element lacking in all three programmes discussed, and appears prevalent throughout the sector as a whole. The time required to maintain these programmes is something that needs to be better understood in the WASH sector as a whole.

The result of the current system amounts to a vicious circle where the funding paradigm of the sector does not allow sufficient time for the implementation process to establish legitimacy for benefits that are not immediately tangible. The current system seeks demonstrable results in the short-term in order for the implementing bodies to receive funding. With emphasis on the short-term, the long-term future is neglected and not properly supported. Programmes eventually fail, prolonging the high incidence of failure, resulting in continued demands from donors for immediate success.

Implementing organizations and donors must develop patience and understanding of the social construction of reality in order to allow longer timelines at the implementation phase. Programmes must establish a foundation for success by legitimating the desired activities through tangible benefits to communities that become part of a revised value emphasis. More importantly, programmes must be allowed sufficient time for a plausibility structure to be legitimated and, in turn, maintained. 
By applying the literature to the theory presented in the last chapter, this chapter has demonstrated that programmes are not sufficiently taking into account the importance of the sociological factors necessary for long-term adoption of WASH practices. Additionally, it also showed that had these programmes made better implementation of the sociological factors described in chapter three, the exemplars would have likely been successful. This chapter also demonstrated that nothing can be built if the preceding step is missing. Specifically, recognizing the social construction of reality should be considered the first step for any programme to have a chance of achieving long-term success. Changing the subjective aspects of programmes to ensure individuals choose to continue the WASH practices can only begin from programmes that seek to change the social as well as the physical components of a community.

Communities need to be considered akin to systems continuously seeking stability. Programmes must ensure that improved practices are supported in a way that aligns the needs of society and its members for the least resistance from other elements of the social system. Programmes must look outwards at the enabling elements that support the subjective decisions that individuals make because the community is only part of a larger system. Only when these issues are addressed will the resistance from other components truly be addressed.

Addressing the subjective components that reinforce the current system will require programmes to target the value emphasis of the communities. Commonly, the choice to continue WASH practices is disregarded in favour of more tangible consequences because the WASH practices or the belief in the benefits of the practices, are not valued sufficiently. To avoid these shortfalls, the value emphasis of the 
community must shift away from the generally low priority afforded to water and sanitation. In so doing, the norms and beliefs of the community will follow the change in value emphasis and, in time, will reinforce the changed value emphasis. Greater priority for WASH practices will become reinforcing elements of the system, which would not be possible without the programme taking into consideration the social construction of reality.

Assuming that programmes are able to shift the value emphasis, the practices must still be made plausible to the local communities. A plausibility structure is required to support the legitimation and maintenance of the WASH practices so that all that is socially constructed can be internalized and accepted as being congruent with the revised system. Legitimation is possible and was demonstrated by the response from communities to continue the WASH practices after seeing the effectiveness of the programme when data was collected. Conversely, attempts to legitimate by attaching rewards to the improved practices backfired, resulting in decreased value ascribed to the WASH Practices. A plausibility structure that legitimates the revised value emphasis is necessary to support the improved practices, increasing the likelihood that the community will actively choose to continue the programme for the long-term. On the other hand, neglecting to establish or revise the plausibility structure to support the improved WASH practice, means there is nothing to be built on and subsequently nothing to be maintained.

With a plausibility structure supporting the legitimacy of the WASH reality, each new generation will be raised to only know the WASH reality. As such, there is a much greater chance that the practices will be accepted and unquestioned as time goes on. In all three examples described, none of the programmes had effectively revised the value 
emphasis or legitimacy of the WASH practices and left nothing to maintain following the implementation phase of their respective programmes. This fact is not intended to discount the important role that maintenance has in ensuring the long-term success of WASH programmes.

Assuming that the implementation phase is capable of revising the value emphasis and legitimating the practices to establish a plausibility structure, both will require maintenance in the face of challenges and human forgetfulness. Ensuring the subjective aspects of the community are targeted during implementation will be one of the most effective tools for maintenance once implementation is completed. Demonstrating value in WASH practices will support the subjective elements necessary to ensure individuals continuously choose the WASH practices. Support from the entire system, especially beyond the community, will be necessary to ensure that programmes are able to achieve this. More patience, time and financing must be afforded to programmes in order to get the implementation right. More importantly, the programmes must be congruent with the social reality of the community. Programmes cannot manufacture their own success while ignoring the capacity for the community to continue the programme once implementation is completed because these elements will not be there when the implementing body leaves the community. Given that the only opportunities for programmes to create mechanisms for maintenance are during the implementation process, the best forms of maintenance will arise from what programmes establish to prevent communities from reverting to the previous practices. Most of all, programmes must abstain from implementing realities that communities cannot maintain on their own. 
Looking specifically at the exemplars in light of the theory presented in chapter three, a number of trends are evident. Primarily, the scope of the community or enabling environment approach is too shallow. In all three exemplars, it is clear that after the implementation phase community members are not choosing to adopt the new practices. It is also evident that only looking within the community for factors to influence the enabling environment solutions are similarly too narrow. All three programmes came at this approach differently yet yielded the same failed results. Solutions to these challenges will likely not be found within the communities and better solutions may come from addressing how programmes are being delivered.

All three exemplars also demonstrated instances of overinvestment of time and resources during implementation followed by a lack of similar investment and support following the implementation. In all three of the programmes examined, the initial injection of funds created a situation where the programmes were operating at a level that the communities could not match on their own. The programme in Guatemala ran out of funds focusing on the physical components of the programme, only completing half of the construction goals and the community abandoned the practices completely. The other two programmes created the conditions for success upfront but failed over the long-term, as communities could not afford to continue the programmes as designed or chose not to invest the funds in WASH. These scenarios indicate that programmes are not investing in the necessary elements to convince communities to continue the improved practices and are lacking investment in mechanisms to support communities post-implementation.

Furthermore, in all three examples, funds were limited to the initial construction and implementation only. This set unrealistic expectations from the outset of the 
programme and provided little in the way of a tangible reality for community members to continue when the implementation was complete. It is important that programmes abstain from creating false conditions that the communities cannot possibly continue.

A persistent lack of coordination among programmes and groups implementing the programmes is another challenge demonstrated by the exemplars. It is recognized that each community is different and has different needs, both culturally and geographically, but there remains much fragmentation between groups implementing the programmes as well as the types of programmes being delivered. For example, the programme in Guatemala arguably left the community in worse shape than it was before the implementing group approached the community. These sorts of programmes should never be implemented. They are dangerous for the sector and, when they fail, they diminish the value afforded to WASH practices. The CLTS programme in Malawi is another example of incoordination as there were different implementing bodies operating in neighbouring communities providing conflicting information to the local populations resulting in at least one of the communities stopping participation in the programme. Better coordination between programmes and implementing bodies is necessary to help remedy these barriers that exist outside of the community, but pose a risk for programme success.

Finally, in two of the examples, poor governance and lack of political influence noticeably hindered programme success. Government support is often considered an important enabling element that is necessary to ensure WASH programmes can succeed. On the other hand, the examples demonstrated instances with different levels of government support and commitment. In the example in Malawi, government support 
was not able to keep up with the level of funding provided by the implementing groups. Although it seemed that a lack of government funding was the principal reason for programme failure, it was instead shown to be untrue. The budget provided by the government was insufficient, but this was not made clear to the implementing groups until the end of implementation. For the WASH in Schools pilot in Kenya, a lack of government support was also not the only reason for failure, but more certainly could have been done at the administrative level to ensure that school headmasters continued to support the programmes. Perhaps, due to lack of political will, awareness or interest, these pilot programmes did not tie any goals or targets related to WASH to the performance indicators of the headmasters, which could have been a relatively easy way to ensure that the programmes were continued and that the funds were spent on WASH products and repairs, as needed. Lastly, in Guatemala, there was a complete lack of government support.

All of these issues are beyond the reach and scope of programme implementation. Addressing these challenges must be considered at the policy level when programmes are being planned and developed. Learning from these mistakes may provide greater opportunities for future programmes to succeed where the examples described in this document failed. But for a chance to succeed, programmes will need to change in a manner that fits the theory outlined in chapter three. 


\section{Chapter: Conclusions}

This document began by demonstrating how an adequate quantity and quality of water is crucial to improving the living conditions for the 780 million people who lack water and the 2.5 billion who lack sanitation worldwide. The first chapter explained how large disparities exist within the realms of water access and sanitation predominantly affecting poor and rural populations of developing countries, denying the benefits and opportunities that come with improved access to water and sanitation. It was also demonstrated that it is now time to address these water-related challenges as the quality of the world's water is increasingly threatened by increase in water usage related to population growth, industrial and agricultural expansion and the effects of climate change on the earth's hydrologic cycle.

The first chapter also revealed the importance of improving access to water and sanitation towards the Millennium Development Goals (MDGs), with a timeline for completion in 2015, and progress is currently off track for meeting the water and sanitation targets. The tremendous social and economic benefits coinciding with the completion of the MDGs were also demonstrated, which, for developing countries, represents a remarkable potential for GDP growth, whereas for citizens, it represents the ability to break the cycle of poverty and live healthier, more productive lives. Overall, there is much to be gained from improving access to water and sanitation to better the lives of the global population who lack it, particularly as population growth and climate change are expected to create unprecedented strains on water, leaving massive numbers in water scarce conditions. 
Chapter two introduced Water Access, Sanitation and Hygiene (WASH) programmes as a valid solution to the water crisis, and an important component towards accomplishing the MDGs. By leveraging the benefits of water access and sanitation with hygiene promotion, WASH programmes provide communities with the tools necessary to keep water clean and reduce the risk of water-related infections. Since their inception in the 1960s, WASH programmes have continually adapted to improve on how to provide communities with clean and safe water alongside reduction of those without access to adequate sanitation, as well as those who do not use either of these facilities despite their availability.

Notwithstanding these efforts, progress towards the MDGs for water and sanitation are off track, and WASH programmes are consistently failing to achieve success with estimates indicating between 30 to 50 percent of all programmes fail. As a result, programmes are rarely being scaled to a level that facilitates larger implementation, and when they are, the high rate of failure is scaled up as well. To help demonstrate this and provide examples for analysis in the later chapters, three exemplars of failed programmes were detailed, revealing the different ways WASH programmes can fail. These exemplars have little in common other than being based on the same WASH ideals; a different group implemented each, at a different time and in a different global region. Yet despite these significant differences, all three failed to ensure long-term adoption of WASH-related practices among their respective target populations. Looking at the water and sanitation sector as a whole, the literature offers numerous reasons for this failure, yet programmes continue to fall short of projected goals with no compelling explanations. 
Based on this assessment, it was then proposed that a compelling reason for this is because WASH programmes appear to be perpetuating the same challenges without addressing the root causes of why programmes are failing, suggesting that something in the equation is missing. The chapter concluded by suggesting that the answer may lie undeveloped and ignored in the literature on WASH, but lacks the theoretical framework to uncover it.

Chapter three identified and explicated a theory implicit in the WASH literature by contextualizing commonalities in the data presented in chapter two. The goal of WASH programmes is to bring about social change within the target populations by redefining their normative water and sanitation activities. As such, it was suggested that long-term change in human actions must be considered in terms of how social change happens within a social system. In systems, components resist change because they are mutually reinforced by, and reinforcing of the other components. For WASH programmes, the target populations exist in a social system that, by virtue of this "systemness", resists change to preserve the stability of the overall system.

WASH programmes approach these systems, or communities, with suggested new patterns of activity for water and sanitation. Through WASH programmes, practitioners arrive at these communities and objectify and externalize new patterns of activity in the hope that populations will internalize them and eventually replace the previous activities. The intended outcome is to define a new nomos for water and sanitation-related activities for these populations. Predictably, resistance from the communities towards the new nomos is often too great, and the WASH-related practices are not continued long-term. When programmes fail to instill the new WASH activities in the target population, it is 
because programmes are not successfully changing the nomos for water and sanitation activities.

When the new nomos is not accepted, often it is because programmes are too narrow in scope, not factoring in the many social influences that define the reality of the communities. It is not enough to simply design the programme for the entire community as a means of addressing this social element, as many programmes do. The new reality must be made plausible to the population in order for the new activities to become taken for granted and practiced routinely. It was then demonstrated how a plausibility structure makes this possible by aligning the institutions of the social system in a way that reinforces the new reality, allowing it to be internalized and taken for granted.

Similarities to the concept of a plausibility structure are inherent in programmes that employ an enabling environment approach, yet as evidenced in chapter two, these programmes are also failing without concrete knowledge of why that is the case. The missing element explained in chapter three suggests that legitimation is first necessary to support a revised plausibility structure for WASH. Legitimation gives credibility and a sense of importance to the social institutions of the plausibility structure, allowing them to be taken for granted and accepted as "self-evident" to all. Legitimation allows the system to become ubiquitous, with new generations raised to share in the reality and accept it as the only way.

In the case of the enabling environment approach, which is designed to create supports for continued WASH practices, only targeting external elements of programmes neglects the importance of value emphasis, which subjectively reinforces the beliefs and 
norms shared by members of the social reality. A value emphasis that does not legitimate the WASH practices ensures that the community reverts to the previous activities.

As such, the overarching social system must be addressed as the source of what is driving the underlying value emphasis, beliefs and, ultimately, the normative activity of individuals. Seeing and understanding the tangible benefits of WASH practices will, over time, improve the health and quality of life for those practicing them. Alternatively, unsuccessful programmes will likely have failed to include one or more of these important sociological factors, which is why the WASH practices were not adopted longterm.

By applying the theory developed in chapter three to the exemplars in chapter two, it was then demonstrated that programmes are not giving communities a chance to have activities accepted long-term because they are not sufficiently addressing the underlying social elements that drive human activity. As such, it was argued that ensuring individuals choose to continue the WASH practices can only begin from programmes that seek to change the social as well as the physical components of a community.

Primarily, it was demonstrated that programmes must be based in the reality of the target communities. In all three of the exemplars, the programmes did not adequately tailor the implementation in line with the social reality of the communities. Specifically, unrealistic goals were set during implementation followed by a lack of investment and support following the implementation. In addition, inflated levels of resources during implementation meant the programmes were operating at a level the communities could not match on their own resulting in environments not plausible to the existing social reality. This set unrealistic expectations from the outset of the programmes and provided 
little in the way of a tangible reality for community members to continue following implementation. Without continued funding it is not possible for the communities to see tangible benefits, which resulted in the programmes becoming susceptible to reversion to the old practices, which is to be expected considering how social systems resist change.

The analysis also revealed how the expectation of WASH programmes, that communities will continue the WASH-related practices, does not consider the various interrelated components that encourage the previous activities. This is because the other components of the social system, such as the polity, local economy or belief system, remain unchanged following the completion of a WASH programme and indirectly encourage a return to the previous practices.

Given that social systems achieve stability by aligning the needs of individuals with society, the barriers to the uptake of WASH practices that were described in the exemplars were evidently stemming from numerous factors at multiple levels. Thus, the scope of all three of the exemplars, particularly in light of the community-based and enabling environment approaches, were not sufficiently supported to sustain the WASH practices in social systems that were too resistant to the new activities. As a result, the enabling environments that were created to support the WASH activities were largely ignored following the implementation phases, and without any maintenance, they began to fail, eventually allowing communities to revert to the previous unhealthy activities. It was then demonstrated how a revised value emphasis to support the WASH practices could have sustained the WASH activities, yet none of the three programmes effectively did so. This is because under the pre-implementation nomos of these communities, the prevailing value emphasis generally attributed low priority to water and 
sanitation. Specifically, the three examples showed a low priority for water and sanitation reinforced by the social system, which explained why the communities were inclined to revert to the previous non-WASH practices. Instead, these efforts to revise the value emphasis so that the communities sufficiently prioritize water issues will require WASH be made plausible, legitimated and subsequently maintainable.

The exemplars demonstrated the importance that legitimating the new reality plays in the ability for the system to reinforce its interrelated components. The value emphasis generates beliefs that further justify and reinforce the value emphasis of the society. Because of this relationship it would be impossible to implement sustained WASH-related activity changes within a community, without also addressing the underlying system that justifies and reinforces the beliefs and norms of the target community.

Finally, none of the programmes effectively established a plausibility structure to maintain and support the new reality. Despite programmes that had external support and incorporated an enabling environment approach, communities still abandoned the WASH activities; the exemplars failed to legitimate the practices through tangible benefits that were plausible to the social reality of the communities. Whereas the exemplars demonstrated instances with different levels of government support and commitment, which they considered to be the reason the programmes failed, as the analysis in chapter four demonstrated, it was actually the lack of a plausibility structure to support the WASH practices that was the principle reason the programmes failed. A revised plausibility structure for WASH would have been able to support the revised value emphasis, and in time, allow the practices to be accepted without question, thereby 
ensuring the WASH practices became integral components of the social reality of these communities. Based on this analysis, it was concluded that WASH programmes fail because they are not creating a new nomos for WASH practices, are not effectively creating a plausibility structure that enables and supports the persistence of the WASH practices and are not adequately changing the value emphasis that would legitimate and maintain the practices over time.

Whereas the subject of WASH is typically studied from a wide range of academic and practical fields, sociology is rarely one of them. Despite this, the sociological analysis herein provides an ostensibly useful analytical tool to approach the problem from another, perhaps overlooked, perspective. In this case, from the perspective of a sociological theory that unifies the otherwise disparate and inconsistent literature on WASH, providing a macro-level view and allowing the identification of patterns present in the literature.

Overall, this sociological perspective makes a different contribution to the water and sanitation sector that is otherwise absent at the moment. This perspective shifts the focus to the social system that is underlying human activity, rather than other efforts that are typically looking at ways of accomplishing the same noble goals of successful programmes, and providing populations with greater access to clean water and sanitation. In the field of psychology, efforts are ongoing to develop better approaches for how to best support and convey the importance of continuing the WASH practices among the populations of these communities (cf. Mosler et al., 2012; USAID, 2010). There is also a significant body of literature in health-related fields concerning water and sanitation, particularly with respect to studies of knowledge, attitudes and practices (KAP), which 
also consider how to affect long-term activity change in populations (cf. Kermode et al., 2005; Schuster-Wallace et al., 2008). Engineers and numerous NGOs are developingways to develop facilities that last with minimal maintenance needed (cf. Johnston, et al. 2012; Messmer \& Luthi, 2012). Biologists are looking at ways of recycling human waste as an alternative to more expensive fertilizers, and other multidisciplinary groups are working on alternative financing models to help these populations and villages develop local economies to support water and sanitation (cf. Davis et al., 2008; Diener et al., 2012; Mehta \& Knapp, 2004).

The sociological theory offered in this document lends itself to many of these aforementioned fields due to the applicability of looking at the social system and tailoring implementation accordingly, followed by mechanisms to ensure the changes are supported long-term. Most importantly, the results of this research may be applied to ongoing or new WASH programmes. If applied from the early stages of programme design, it offers the best chance of future programmes succeeding. This is because it is now clear why WASH programmes are failing to achieve long-term success, and it is clearer what needs to be done so that WASH programmes become the catalysts for longterm solutions, rather than the solutions, in and of themselves.

Specifically, there are four broad recommendations that can be drawn from this research, which should be useful for ongoing programmes, as well as new programmes yet to be developed. Primarily, programmes that provide all of the up-front resources are creating the conditions for failure, rather than success. By injecting resources at the outset, programmes are often operated in conditions that are not able to be maintained following implementation because the injection of resources is not based in the social 
reality of these communities. In these instances, the implementation may appear a success upon completion, but only appears so under false pretenses. When implementation is completed the NGO walks away from a successful project, while the underlying social factors necessary to support and maintain long-term activity change are being overlooked.

This research has shown that communities have the capacity to fund their own development, and to do so these communities must sufficiently prioritize the changes to reallocate their scarce resources away from areas that have, in the past, demonstrated greater tangible rewards. For this to happen in relation to WASH, communities must learn to value water and sanitation enough to prioritize their limited funds in these domains. Programmes must, therefore, legitimate the WASH practices by demonstrating tangible benefits associated with water and sanitation. The only time to accomplish this is during the implementation stage of a programme. If the social system is not altered during implementation, then it is almost assured the community will revert to the previous practices. Failed interventions increase the probability that future interventions in the same communities will be even more susceptible to failure.

The second recommendation pertains to the risks of getting the implementation phase wrong. This research has shown how failed programmes pose a significant risk to diminishing the value emphasis communities place on water and sanitation. It must, therefore, be emphasized that not all forms of intervention are helpful. When programmes inadvertently lower the value attributed to water and sanitation, it makes future water and sanitation development an even more challenging task. USAID (2011) considers that years of paternalistic programmes have created a culture where communities view water 
access, and particularly sanitation, as something provided by foreign governments or development groups, free of charge. WASH programmes that fail to shift the value emphasis placed on water and sanitation risk leaving the communities with a perceived lowered value for these activities. Often the result is communities believing water and sanitation should be provided for free making them less likely to allocate their own funds for water and sanitation, and similarly unlikely to accept assistance from future programmes that require upfront costs. Once again, this underscores the importance of programmes being implemented properly the first time, and that future programmes are cognizant of these risks and plan accordingly.

Given the importance of the implementation stage and the risks associated with programme failure, a discovery phase prior to implementation would be beneficial to determine whether a nomos is changeable, and if so, how to best target social change in these communities. The post-implementation social reality of the community must be congruent with the pre-implementation reality, and a discovery phase will determine which communities are good candidates. Specifically, when the implementing body leaves the community, the continuation of the practices should not require anything beyond what the pre-implementation reality supported, except for the changed value emphasis and plausibility structure. For example, in the Kenyan case involving Lake Victoria, a discovery phase might have indicated the futility of a water source in the forest that no one would use; on the other hand, efforts might have been more effective at improving the existing water access point via a pump and filtration system at the community meeting point at Lake Victoria. This alternative may have been more expensive or required more maintenance, but would have been more effective at 
legitimating the improved practices and revising the value emphasis accordingly, and therefore a better use of programme funds.

Planning accordingly is easier said than done, particularly for the NGOs and implementing organizations that typically approach the subject of water, sanitation and hygiene from a developed perspective. The vast majority of North Americans and Europeans have been born into conditions with running water and domestic plumbing, in addition to being socialized from an early age to the importance of hygiene; whereas, the populations in developing countries have not been born into the same standards.

These populations are capable of creating sanitation and hygiene, especially when facilitated by WASH programmes providing the requisite tools and facilities to do so; yet they still go unused. It is important to recall that sanitation and hygiene practices had to be learned, understood, perceived as necessary and, most of all, proliferated in developed countries. While it can be argued that many of these methods were of a sordid nature, the fact remains that they were developed over time in ways that were consistent with the respective social systems and, perhaps more importantly, within the reality of these societies. Facilities had to be built and engineered, municipal and domestic plumbing had to be planned and constructed and hygiene and proper sanitation had to be taught.

Today, over 95 percent of the population of developed countries is raised with running water and improved sanitation, easily taken for granted as the way it has always been (WHO/UNICEF JMP, 2012). For these countries, finance is the cornerstone of sustainable water and sanitation services, as the costs have become so integrated into the way of life among developed countries that it is easy to take for granted that taxes and tariffs are what pay for continued water and sanitation services. Conversely, WASH 
programmes need to achieve a similar level of ubiquity. This is only possible with a revised value emphasis from which revised beliefs and norms can emerge within an established plausibility structure that supports WASH. If there is anything to be learned from the inequality of water and sanitation services in developed countries it is that societies associate legitimacy with longevity.

Unfortunately, this sort of long-term thinking is not congruent with how WASH programmes are being designed and implemented. These lessons are seldom reflected in the design of WASH programmes that, for the most part, are delivered with tight timelines, limited resources, fragmented approaches and poor, if not non-existent, data collection. ${ }^{16}$ One of the principal reasons for this is because most WASH programmes face a precarious relationship with time and resources. For the vast majority of organizations implementing WASH programmes, resources are limited and generally tied to funding agreements with foreign aid agencies. The result is that the greater the length of time required for implementation, the greater the cost of the implementation and the fewer the resources available for initiatives in other communities. Foreign aid donors want to fund programmes that work and provide the best value for money, which means the more ambitious programmes are often more likely to see funding. The result is unrealistic timelines that do not allow sufficient time for the WASH practices to establish a sense of long-term legitimacy among the target populations.

As a final recommendation, practitioners must recognize that there is no quick fix for improving water and sanitation conditions. Programmes that provide free

\footnotetext{
${ }^{16}$ For more information on the importance of data collection regarding water and sanitation please refer to Epstein (2007) to see how data collection and mapping revolutionized water and sanitation in 19th century London.
} 
infrastructure and the required supplies are, at best, short-term solutions to a considerable long-term challenge. Furthermore, short-term rewards such as the bottle of Fanta for ending open defecation are counterproductive to long-term change. Whereas some shortterm rewards are sometimes used to build rapport and provide incentives for acquiring community buy-in, they inadvertently create expectations for short-term reinforcement that cannot possibly be maintained post-implementation.

Achieving long-term adoption of WASH practices requires communities and individuals to maintain access to clean water and improved sanitation in a self-sufficient manner for years after programme completion, and ideally indefinitely. Self-sufficiency will require that programmes create the right conditions to allow the improved practices to be continued long-term. Communities must actively choose to continue the practices, which is contingent upon them seeing value in them. For example, when a programmebuilt hand pumps break, or when the sanitation facilities are full or in need of repair, households and communities must actively and self-sufficiently decide to invest in replacements. Programmes cannot truly be considered successful at encouraging sustainable results until this point is reached.

To achieve this goal, programmes must be allowed adequate time to legitimate the long-term benefits of improved water and sanitation. No amount of free infrastructure, new technologies or short-term reward schemes is going to legitimate the underlying social aspects required for change to the social reality of these communities. Future implementations will need to take into consideration how programmes can support the decision-making processes that confront individuals on a daily basis, and provide ongoing support to ensure continued legitimation until the plausibility structure is revised 
to support the improved practices. Innovative new approaches to WASH programmes are certainly necessary, and future programmes will find greater success by investing the time and resources necessary to design programmes that change the social elements of communities.

\section{Research Limitations and Future Research:}

There were two considerable limitations that affected this research, which were mainly related to decisions for the methodology of this study. From the outset of this research, it was intended to conduct a quantitative analysis in order to uncover trends among successful WASH programmes that could, perhaps, be applied more broadly throughout the water and sanitation sector. There is an overwhelming amount of data on water and sanitation, however very little of this data is reliable and of acceptable quality. Numerous reports and studies overestimate water and sanitation coverage as was demonstrated in chapter two. Additionally, programmes frequently report on successful implementation, yet have no measures to assess the long-term outcomes. The result is that much of the data is questionable or unreliable, making it difficult to discern the good from the bad.

At first glance the amount of data collected and reported within the sector appears in abundance. Uncovering the various layers of the data that exists, and how it is collected, tells a different story. A great deal of data relates to measuring progress towards the MDGs. This is generally measured by how many people have access to a nearby water source, as well as access to improved sanitation and hygiene facilities. Data at this level is common and can easily be found in numerous monitoring and progress 
reports published by the UN, UNICEF, the WHO and the Joint Monitoring Programme. Furthermore all of these organizations provide open access to their online databases, making the data easily accessible.

Whereas data on access and coverage of facilities is easily attainable, problems arose when trying to find data on the use of these facilities. When this data was available, the reliability and accuracy was questionable as it often lacked comparable data to indicate whether or not the facilities are currently in working order. Assuming this level of detail was available, which it often is not, an even more difficult task remained of lining up the actual use with facility functionality. This is essentially the same problem as discussed in chapter two, whereby surveys commonly rate high rates of access and coverage among water and sanitation facilities, yet the reality is a much lower percent because many are broken or in need of repairs.

Finally, in the process of coding the data from various organizations, it became apparent that the use of different definitions, different dates, common overrepresentation and misrepresentation among access and a general lack of reliability would make the analysis very difficult. Ultimately, the quantitative approach was abandoned, as any analysis was sure to be lost in the minutia of different methodologies and the likely incorrect assumption that the data is sound to begin with.

Moving forward, a qualitative approach was adopted, and this was not without its own challenges as well. Specifically, finding examples of failed WASH programmes was a considerable challenge. Although there is a wealth of information on the number of broken facilities and percentages for the frequency that programmes fail, finding detailed case studies of failed programmes for analysis was quite difficult. 
Ultimately, the exemplars were selected based on availability, albeit with some consideration to finding a mix of geographic locations. Ideally, it would have been preferred to use exemplars that provided greater levels of information on the designing of the implementation stages, as well as more information on the specific starting conditions among the communities. Instead, the case studies selected were somewhat limited and selected from reports produced by organizations that could, arguably, be considered outliers among the water and sanitation sector.

The evaluation report from Saboori et al. (2011) documents the experience of a national pilot project of WASH in Schools and was not actually written in the context that explicitly considers the programme a failure. Nevertheless, this report is significant because it provides a detailed account of a large-scale WASH programme years after the initial implementation. As previously mentioned in chapter two, these sorts of studies are rarely conducted.

The example from Guatemala (Breslin, 2010) provides details of another programme that, this time, was specifically identified as a failure. The organization, Water for All, identifies it in a polemical essay damning the failures of the water and sanitation sector as a whole. Although there is no doubt that the organization Water for All is an active player in the water and sanitation sector, its position certainly differs from other more traditional groups implementing WASH programmes. This is evidenced by the strong argument within the text in favour of WASH programmes that require communities to pay for water and sanitation services.

Finally, the programme illustrated by Nilsson and Kennedy (2012) is very much an outlier, as it originated from an annual publication by Engineers Without Borders 
(EWB) Canada, that highlights failed development projects as potential learning opportunities across a wide range of development sectors. Furthermore, in this particular instance, EWB were not the implementing organization, and the NGO leading the initiative was never named explicitly.

Given the curious nature of these reports and case studies, it begs the question of how it can be so difficult to locate case studies of failed programmes when reports from within the sector estimate as many as one in two programmes fail. The amount of case studies and information available for failed projects appears constrained, yet on the other hand, reports abound of programmes that claim to have achieved success without any proper evaluation after the implementation. The answer to this question, may perhaps be found by future research investigating how programmes measure success, as it is almost certainly related to the statistics presented in chapter two, which demonstrated how misrepresentation of the actual use of facilities is common and how follow-up evaluations are rarely performed.

The far-reaching influence of the measure of success is most apparent when analyzed from the macro-level. How success is measured influences all levels of how WASH programmes are planned, delivered and implemented. Currently, success is predominately measured in terms of access and coverage. Breslin (2010) considers that the water and sanitation sector is almost exclusively focused on measuring beneficiaries of access as a proxy for success. In other words, programmes are considered successful by providing high levels of access to water and sanitation or by meeting coverage targets.

When programmes achieve this form of success they are more likely to receive additional funding allowing the projects to continue and, in some cases, to be scaled up 
among further communities and larger regions. This is because international donors and governments want to fund programmes that work. In doing so, it encourages rushed programmes and rapid results, neglecting anything that is not pertinent to this endeavor.

Although this document argues the importance of incorporating the necessary social elements to encourage long-term adoption of WASH practices, the funding mechanisms inherent within the sector may still pose a considerable challenge towards designing programmes that are given the time necessary to actually succeed.

By measuring success in terms of access, funding becomes most readily available to those programmes and organizations that deliver the most access in the least amount of time. This process trickles down throughout the other levels of the system to reinforce the expediency of timelines and the sector aligns itself to best suit these needs. Practices that would hinder this process, such as data collection, programme evaluations and greater collaboration among, and within, various levels of government and NGOs are not considered as they are not deemed necessary and will only detract from the expediency with which the programmes can be implemented and targets met. The result is that funding decisions may be inadvertently expediting programmes and contributing to their respective failure. Future research in this regard may benefit from an analysis of the water and sanitation sector as a social system to determine how the sector may be perpetuating rushed and unilateral programmes in order to meet its own survival needs.

The community of NGOs, development bodies and governments delivering and designing WASH programmes should be looked at as a social system similar to the communities described in this document. Future analysis of the value emphasis at all levels of the water and sanitation sector may provide additional insight into why 
programmes are failing and how to achieve more successful programmes. National governments need to see the importance of investing and implementing policies to support WASH similar to how individuals need to see the benefits of proper sanitation and hygiene for their own personal actions. Likewise, development agencies and funding bodies need to see the importance of long-term change and have the patience and foresight to demand programmes that work well beyond implementation.

Finally, another area for potential further research comes from the inadvertent focus on programmes and interventions in a rural perspective. Although some of the statistics and programmes mentioned were located in urban areas, the exemplars all consisted of rural programmes. My own research left me with the impression that the majority of the literature and reports on WASH do so from a rural lens. Peal et al. (2011) note this bias while emphasizing that the rapid urbanization common to many developing countries is causing complex water and sanitation problems. Since the 1990s, the proportion of the global population living in urban areas has increased by over 30 percent, and it is expected to reach 60 percent by the year 2020 (Gleick, 2011). As such, WASH programmes are set to face increasing challenges as urban migration is expected to outpace rural-growth. For this reason, there is a growing gap in the knowledge that can be filled by future research to better understand these growing urban challenges and to ensure the design and planning of WASH programmes remains relevant while addressing the underlying social factors that influence decision-making among water-scarce populations. 


\section{Appendices}

\section{Appendix A : Relationship of Water and Sanitation towards the Millennium}

\section{Development Goals}

The Millennium Development Goals (MDGs) consist of eight goals, with each consisting of a number of sub-targets. The targets are measured improvements in the percentage of the populations identified by each goal, using 1990 as the benchmark for comparison. Each goal is measured and the ultimate goal of the MDGs is to meet or exceed all targets by 2015 .

Goal one is to eradicate extreme poverty and hunger, with the target of halving the proportion of people whose income is less than one dollar per day, as well as halving the proportion of people suffering from hunger (United Nations, 2011). Access to water and sanitation is central towards combating poverty and improving the economic outcomes for the world's poorest populations. Making better use of water for agricultural and industrial purposes will increase economic outcomes and the availability of food. Access to water closer to homes will reduce the time spent collecting water and allow for more time to be spent being economically productive, particularly for women (Gleick, 2009).

Goal two is to achieve universal primary education, with the target of ensuring that all children have access to full primary education (United Nations, 2011). Access to water and sanitation is crucial towards improving the educational outcomes for the poorest populations by reducing illness and freeing time for attending school. Waterrelated illnesses often lead to disease and malnutrition, which can have effects on cognitive and physical development among children. School absenteeism is also 
frequently the result of water-related illnesses, from time spent collecting water, or from caring for a sick family member. Providing access to water that is closer to individual dwellings will reduce the time spent collecting water and allow for more time to be spent being economically productive or for education (Gleick et al., 2009).

Goal three is to promote gender equality and to empower women and girls worldwide by eliminating gender disparity in the educational system (United Nations, 2011). Providing access to water and sanitation in schools has direct effects on educational attainment and improving gender equity. For girls, school absenteeism is often the result of tending to a sick family member, or fetching water as part of the domestic household duties, which is disproportionately the responsibility of girls and women. Girls will also miss school after reaching menstrual age because there is often no private place to use a toilet at school. Therefore, lack of access to water and sanitation is a significant barrier for women and girls to acquire an education and to subsequently overcome poverty (Gleick et al., 2009).

Goals four and five are health related goals targeting a reduction in infant and motherhood mortality rates. Goal four is to reduce child mortality of children under five years old by two-thirds (United Nations, 2011). Goal five is to improve maternal health by reducing the maternal mortality ratio by three-quarters (United Nations, 2011). Inadequate sanitation and lack of access to clean water are important here as well, as poor sanitation or contaminated water contribute to increased childhood mortality and worsened maternal health. Water-related diseases are among the largest causes of childhood mortality in the developing world. Additionally, women giving birth in unsanitary conditions, and without access to clean water, greatly increases the maternal 
mortality rate (Gleick, 2009). Improving water and sanitation are an important step towards reducing these mortality rates.

Goal six is to stop and begin reversing the spread of HIV/AIDS, malaria and other major diseases (United Nations, 2011). This is also affected by water access and sanitation as water-related illnesses increase the risk of death among those infected with HIV/AIDS. Better management of wastewater and standing water will also greatly reduce the threat of malaria (Gleick, 2009).

Goal seven is to ensure environmental sustainability by integrating sustainable development principles into the national policies and programmes of countries around the world. This goal also sets a target to halve the proportion of people without sustainable access to water and sanitation and also aims to achieve a significant improvement in the lives of at least 100 million slum dwellers (United Nations, 2011).

Goal eight is to develop a global partnership for development, and is comprised of eight different targets for developing countries: improving trading and financial systems, addressing the economic and trading needs, addressing the needs of landlocked or island states, managing debt, promoting productive work for youth, providing access to affordable pharmaceuticals and improving availability of information and communication technology (United Nations, 2011). Improving access to water sources and sanitation are at the foundation to achieve all other MDGs that will similarly facilitate progress on MDG eight as healthy and educated populations will allow national governments to shift emphasis from these other priorities. 
Appendix B : Diagram of the Fecal-Oral Transmission of Germs and Ways to Break the Transmission Route

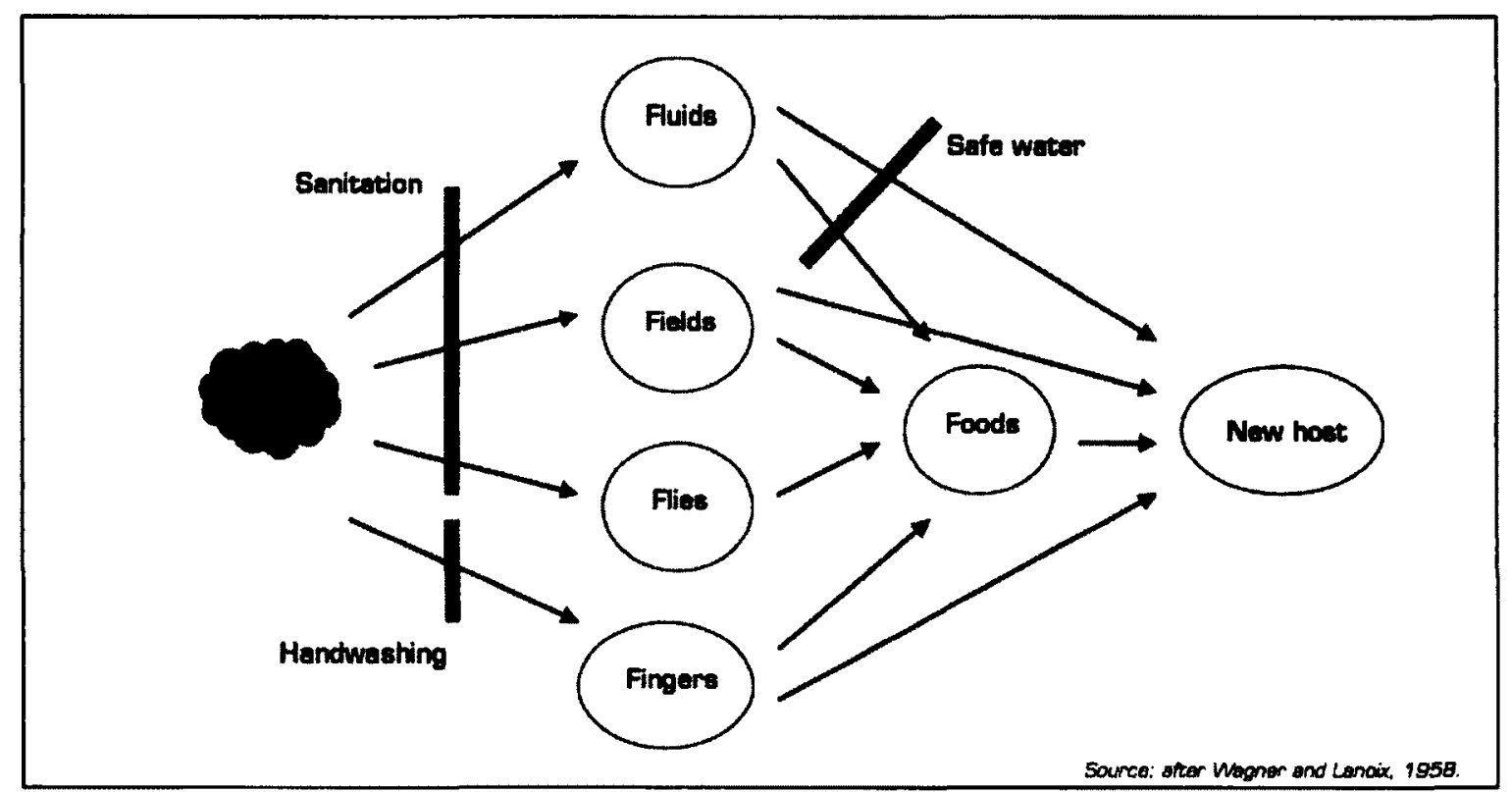

Source: Peal et al., 2010 


\section{Bibliography}

Adams, J., Bartram, J., Chartier, Y., \& Sims, J. (2009). Water, Sanitation and Hygiene Standards for Schools in Low-cost Settings. Geneva: World Health Organization.

Adhikari, S., \& Lal Shrestha, N. (2008). School Led Total Sanitation: A successful Model to Promote School and Community Sanitation and Hygiene in Nepal. Beyond Construction: A collection of case studies from sanitation and hygiene promotion practitioners in South Asia, London, UK, WaterAid and Delft, The Netherlands, IRC International Water and Sanitation Centre, 114-125.

Bartram, J., \& Cairncross, S. (2010). Hygiene, Sanitation, and Water: Forgotten Foundations of Health. PLOS Medicine Policy Forum, 7(11), 1-9.

Berger, P. L. (1967). The Sacred Canopy: Elements of a sociological theory of religion. Garden City: Anchor Books.

Berger, P. L., \& Luckmann, T. (1966). The Problems of the Sociology of Knowledge and Realities of Everyday Life. Garden City, NY: Doubleday.

Blue Planet Run Foundation. (2012). Blue Planet Run Foundation. Retrieved December 3, 2012, from What Makes Clean Water So Important?:

http://blueplanetnetwork.org/water/

Breslin, E. D. (2010). Rethinking Hydro-Philanthropy. Denver: Water for People.

Caso, F. (2010). Freshwater Supply. New York: Facts on File.

Clarke, R., \& King, J. (2004). The Water Atlas. New York: The New Press.

Cooley, C. H. (1909). Social Organization: a study of the larger mind. New York: C. Scribner's sons.

Curtis, V., \& Cairncross, S. (2003). Effect of washing hands with soap on diarrhoea risk in the community: a systematic review. Lancet Infect Dis., 3(5), 275-281.

Davis, J., White, G., Damodaron, S., \& Thorsten, R. (2008). Improving access to water supply and sanitation in urban India: microfinance for water and sanitation. Water Science \& Technology, 58(4), 887-891.

Diener, S., Reiser, J., Murray, A., Mbeguere, A., \& Strande, L. (2012, July). Recovery of Industrial Waste Heat for Faecal Sludge Drying. Sandec News, 13.

Durkheim, E. (1933). The Division of Labor in Society. (G. Simpson, Trans.) New York: Free Press. 
Durkheim, E. (1982). The rules of sociological method. (S. Lukes, Ed., \& W. Halls, Trans.) New York: Free Press.

Engineers Without Borders Canada. (2012). Failure Report 2012. Toronto: Engineers Without Borders Canada.

Epstien, H. (2007, June 28). Death by the Numbers. The New York Times Review of Books.

Gleick, P. H. (2005,17-March). Water for Schools: A Proposed Global Initiative. Retrieved July 13, 2011 from Pacific Institute: http://www.pacinst.org/topics/water_and_sustainability/water_for_schools/

Gleick, P. H., Allen, L., Christian-Smith, J., Cohen, M. J., Cooley, H., Heberger, M., et al. (2011). The World's Water 2010-2011: The Biennial Report on Freshwater Resources. Washington: Island Press.

Gleick, P. H., Cooley, H., Cohen, M. J., Morikawa, M., Morrison, J., \& Palaniappan, M. (2009). The World's Water 2008-2009: The Biennial Report on Freshwater Resources. Washington: Island Press.

Goffman, E. (1959). The Presentation of Self in Everyday Life. Garden City: Doubleday.

Harris, M. (1979). Cultural Materialism: the struggle for a science of culture. New York: Random House.

Harris, M. (1966). The Cultural Ecology of India's Sacred Cattle. Current Anthropology, 33(1), 261-276.

Huber, A. C., \& Mosler, H.-J. (2012, July). Determining behavioral factors for interventions to increase safe water consumption: a cross-sectional field study in rural Ethiopia. International Journal of Environmental Health Research, 23(2), 96-107.

Hutton, G., \& Laurence, H. (2004). Costs and Benefits of Water and Sanitation Improvements at the Global Level. Geneva: WHO.

International Water and Sanitation Centre. (2009, November 17). PRESS Release: IRC International Water and Sanitation Centre to pilot new model to improve rural water services. Retrieved December 3, 2012, from International Water and Sanitation Centre: http://www.irc.nl/page/48048

International Water and Sanitation Centre. (2007). Towards Effective Programming for WASH in Schools: A manual on scaling up programmes for water, sanitation and hygiene in schools. Delft, the Netherlands: IRC International Water and Sanitation Centre. 
International Water and Sanitation Centre. (2011). We Have Failed on WASH in Schools. Retrieved July 4, 2012, from IRC E-Source WASH News and Features: http://www.createdebate.com/debate/show/We_have_failed_on_WASH_in_Schools IRC International Water and Sanitation Centre and WaterAid. (2008). Beyond Construction: Use By All A collection of case studies from sanitation and hygiene promotion practitioners in South Asia. IRC and WaterAid.

Johnston, R., Derksen-Muller, S., Peter-Verbanets, M., Pronk, W., \& Krohn, M. (2012, July). Building a Better Filter - Combining Research and Design. Sandec News, 13.

Kalimuthu, A., \& Hossain, Y. (2008). Community-led total sanitation is the best method of achieving sustainable sanitation for all in rural areas. Waterlines, 27(3), 177-183.

Kennedy, M., \& Nilsson, K. (2012). The Goat is to be Hallal: Field Level Lessons on Scaling Community-Led Total Sanitation. In Engineers Without Borders Canada, Failure Report 2012 (pp. 12-13). Toronto: Engineers Without Borders Canada.

Kermode, M., Holmes, W., Langkham, B., Santhosh Thomas, M., \& Gifford, S. (2005). HIV-related knowledge, attitudes \& risk perception amongst nurses, doctors \& other healthcare workers in rural India. Indian Journal of Medical Research, 122, 258-264.

Makemba, A., Winch, P., Makame, V., Mehl, G., Premji, Z., Minjas, J., et al. (1996). Treatment practices for degedege, a locally recognized febrile illness, and implications for strategies to decrease mortality from severe malaria in Bagamoyo District, Tanzania. Tropical Medicine \& International Health, 1(3), 305-313.

Maslow, A. H. (1954). Motivation and Personality. New York: Harper.

Mehta, M., \& Knapp, A. (2004). The Challenge of Financing Sanitation for Meeting the Millennium Development Goals. Nairobi: Water and Sanitation Program.

Messmer, U., \& Luthi, C. (2012, July). The Challenge of Reinventing the Toilet. Sandec News, 13.

Mosler, H.-J. (2012). A systematic approach to behavior change interventions for the water and sanitation sector in developing countries: a conceptual model, a review, and a guideline. International Journal of Environmental Health Research, 19(1), 1-19.

Mosler, H.-J., Huber, A., Inauen, J., \& Tobias, R. (2012, July). How to Achieve Evidence-Based Behavioural Change. Sandec News, 13.

Nakagawa, M. (2009, March 18). Investing in Clean Water Brings Economic Benefits and So Much More. Retrieved August 14, 2011 from Natural Resources Defense Council 
Switchboard:

http://switchboard.nrdc.org/blogs/mnakagawa/why_we_should_support_funding.html

OECD. (2011). Benefits of Investing in Water and Sanitation: An OECD Perspective. http://dx.doi.org/10.1787/9789264100817-en: OECD Publishing.

Pareto, V. (1966). Sociological Writings. London: Pall Mall Publishing.

Parsons, T. (1968). On the Concept of Value Commitments. Sociological Inquiry, 38(Spring), 135-160.

Peal, A., Evans, B., \& Van Der Voorden, C. (2010). Introduction to Hygiene and Sanitation Software: An Overview of Approaches. Water Supply \& Sanitation Collaborative Council. Geneva: Water Supply \& Sanitation Collaborative Council.

Pokharel, M. (2012, April). South Asia Regional WASH in School Conference Report. Retrieved December 3, 2012, from WASH in Schools Mapping: http://washinschoolsmapping.com/pdf/South_Asia_Conference_Report_April_2012.pdf

Robinson, A. (2005). Improving hygiene and sanitation behaviour and services. Technical guidance to the World Bank/Indonesian Government/Indonesia's Ministry of Health team in the preparation of hygiene and sanitation promotion components for the proposed National Program for Community Water Supply and Sanitation Services Project. Jakarta: World Bank.

Rural Water Supply and Sanitation Project Western Nepal. (2009, November). Rural Water Supply and Sanitation Project Western Nepal: Project Brief. Retrieved December 3, 2012, from District WASH Support: http://www.ncf.org.np/upload/files/761_en_1.pdf

Saboori, S., Mwaki, A., Porter, S. E., Okech, B., Freeman, M. C., \& Rheingans, R. D. (2011). Sustaining school hand-washing and water treatment programmes: Lessons learned and to be learned. Waterlines, 30(4), 298-311.

Schuster-Wallace, C. J., Grover, V. I., Adeel, Z., Confalonieri, U., \& Elliott, S. (2008). Safe Water as the Key to Global Health. Hamilton: United Nations University.

Skinner, J. (2009). Where every drop counts: Tackling Rural Africa's Water Crisis. London: International Institute for Environment and Development. International Institute for Environment and Development.

Sugrue, D., \& Pfluger, A. (2012, April 19). Water and Sanitation: Decisive Effects in Modern Operations. Retrieved December 3, 2012, from Small Wars Journal: http://smallwarsjournal.com/jrnl/art/water-and-sanitation-decisive-effects-in-modernoperations 
Tamas, A., \& Mosler, H.-J. (2011). Why Do People Stop Treating Contaminated Drinking Water With Solar Water Disinfection (SODIS)? Health Education \& Behavior, 38(4), 357-366.

Tandon, N. (2007). Biopolitics, climate change and water security: impact vulnerability and adaptation issues for women. Agenda, 73, 4-19.

Taylor, L. (2011, July). No Pads, No School: Girls' Education Going Down the Toilet. Retrieved August 14, 2011 from Think Africa Press:

http://thinkafricapress.com/health/girls-education-threatened-lack-sanitary-facilities

The World Bank. (2010). Water and Development: An Evaluation of World Bank Support 1997-2007. Washington: The World Bank.

Thomas, W. I. (1923). The Unadjusted Girl: with cases and standpoint for behavior analysis. Boston: Little.

Ulrich, L. (2012). Comparing Costs of On-Site Sanitation Infrastructure in Asia and SubSaharan Africa. Sandec News, 13, 7.

UNESCO. (2006). Water: A Shared Responsibility. New York: Berghahn Books.

UNICEF. (2011, May). Call to Action for WASH in Schools in Europe. Retrieved December 3, 2012, from Water, Sanitation and Hygiene:

http://www.unicef.org/wash/schools/files/Concept_note_WASH_in_Schools_Partnership _Meeting_20110317.pdf

UNICEF. (2012, March). Soap Stories and Toilet Tales from Schools: 19 Web Stories. Retrieved December 3, 2012, from WASH in Schools Mapping: http://www.washinschoolsmapping.com/pdf/UNICEF_2011_SoapStoriesV11_web.pdf

United Nations Development Programme. (2006). Human Development Report 2006. New York: United Nations Development Programme.

United Nations Development Programme. (2005). Investing in Development: A Practical Plan to Achieve the Millennium Development Goals. United Nations Millennium Project. Sterling: Earthscan.

United Nations. (2011). The Millenium Development Goals Report 2011. New York: United Nations.

USAID. (2010). Access and Behavioural Outcome Indicators for Water, Sanitation, and Hygiene. Washington: USAID Hygiene Improvement Project. 
USAID. (2010). The United States' Strategy for Meeting the Millennium Development Goals. Washington: USAID.

Water for People. (2013, March 22). Every Day is World Water Day: 'Ongoing Service' Versus 'Access'. Retrieved March 28, 2013, from: http://www.good.is/posts/every-day-isworld-water-day-ongoing-service-versus-access

WHO and UN-Water. (2010). UN-Water Global Annual Assessment of Sanitation and Drinking-Water. World Health Organization and United Nations. Geneva: WHO.

WHO/UNICEF JMP. (2012). Progress on Drinking Water and Sanitation: 2012 Update. Geneva: WHO Press.

WHO/UNICEF JMP. (2010). Progress on Sanitation and Drinking-water: 2010 Update. Geneva: WHO Press.

WHO/UNICEF. (2006). Meeting the MDG Drinking Water and Sanitation Target: The Urban and Rural Challenge of the Decade. New York: United Nations.

Williams, R. M. (1970). American Society: a sociological interpretation. New York: Knopf. 